\title{
Evaluation of CMIP6 Climate Models for Climate Change Impact Assessments in Upper Awash Basin, Ethiopia
}

\section{Selamawit Haftu Gebresellase}

Hohai University https://orcid.org/0000-0002-9162-8244

Zhiyong Wu ( $\nabla$ wzyhhu@gmail.com )

Hohai University

Huating Xu

Shanghai Investigation, Design \& Research Institute Co.,Ltd., China Three Gorges Corporation

Idris Muhammad Wada

Hohai University

\section{Research Article}

Keywords: CMIP6 climate models, climate change, Upper Awash Basin, Ethiopia, GCMs

Posted Date: January 10th, 2022

DOI: https://doi.org/10.21203/rs.3.rs-1231424/v1

License: (c) (i) This work is licensed under a Creative Commons Attribution 4.0 International License.

Read Full License 


\section{Evaluation of CMIP6 climate models for climate change impact \\ 2 assessments in Upper Awash Basin, Ethiopia}

3 Selamawit Haftu Gebresellase ${ }^{1}$ \& Zhiyong Wu ${ }^{1, *}$ \& Huating Xu ${ }^{1,2}$ Wada Idris Muhammad 3

\footnotetext{
$4{ }^{1}$ College of Hydrology and Water Resources Engineering, Hohai University, Nanjing 210098, People's Republic of China

52 Shanghai Investigation, Design \& Research Institute Co.,Ltd., China Three Gorges Corporation, Shanghai, China

$6{ }^{3}$ College of Water Conservancy and Hydropower Engineering, Hohai University, Nanjing 210098, People's Republic of China

$7 \quad$ *Z Zhiyong Wu wzyhhu@gmail.com
}

8 Abstract

9 Identifying GCMs that represent the climate of a specific area is crucial for climate change studies. However, the 10 uncertainties in GCMs caused by computational constraints, such as coarser resolution, physical parameterizations, 11 initializations, and model structures, make it imperative to identify a representative individual or group of GCM for a 12 climate impact study. An advanced envelope-based multi-criteria selection approach was used to identify a subset of 13 the most appropriate future GCMs in the Upper Awash Basin. The skill accounting is based on (1) the range of 14 projected mean changes of climate variables, (2) range of variability in climate extremes and, (3) model run performance to represent historical climate data. Statistical downscaling and bias correction were made for the selected model runs. The downscaled and bias-corrected monthly values for precipitation are expected to increase from $0.42 \%$ to $2.82 \%$ in mid-century and $0.15 \%$ to $3.79 \%$ by the end century considering the SSP4.5 scenario. For SSP8.5, it increases from $1.45 \%$ to $5.51 \%$ and $2.57 \%$ to $9.78 \%$ in the respective periods. Likewise, under the SSP4.5 forcing scenario, the monthly average air temperature projected to be warmer, which increased from $0.68{ }^{\circ} \mathrm{C}$ to $1.55^{\circ} \mathrm{C}$ during mid-century and $0.09^{\circ} \mathrm{C}$ to $1.92{ }^{\circ} \mathrm{C}$ end-of-century. Meanwhile, for SSP8.5, the projection indicates an increment of $0.19^{\circ} \mathrm{C}$ to $1.98^{\circ} \mathrm{C}$ under mid-century and $2.37^{\circ} \mathrm{C}$ to $7.00^{\circ} \mathrm{C}$ end-century. The projected change of future precipitation and temperature in the study basin increases the precipitation intensities, wet days and dry spells due to hightemperature increment. 


\section{Introduction}

Climate change is altering environmental and hydrological systems at global and regional scales. Assessing the spatial and temporal variability of climate data is one of the basic requirements for solving hydrological and water management problems. A significant change in air temperature and precipitation can affect the hydrological system, which can cause disasters like floods and drought (Aich et al. 2014) by altering and hastening the hydrological cycle (Peterson and Halofsky 2018; Reshmidevi et al. 2018). Severe climate extremes such as El Niño may frequently occur in the coming decades, resulting in a significant loss of livestock, crop failure, and serious economic impacts. The increase in climate extremes that highly influence climate variability could increase regions susceptibility to droughts. Ethiopia experienced severe drought in the past decades and most droughts were El Niño induced. The Upper Awash Basin (UAB) is the most utilized and most developed basin in Ethiopia. It is one of the primary water source for urban, industry, hydropower and agriculture in central Ethiopia, including the capital of the country. This is an important basin in the country due to its location in a diverse climatic region. For sustainable water management, it is important to assess the future climate trends and its vulnerability.

General circulation models (GCMs) are numerical models which represent numerous developments in the land surface, oceans and atmosphere. GCMs are the primary input sources for future climate change impact studies and climate patterns assessment. Over the past years, the number of GCMs available for possible future changes has significantly increased. Phase 3 of the Coupled Model Intercomparison Project (CMIP3) (Annan and Hargreaves 2010), which was used for the Intergovernmental Panel on Climate Changes (IPCC) Fourth Assessment Report (AR4), contains climate data output of 25 GCMs, while CMIP5, which was used for AR5, contains climate data of 61 different GCMs (Lutz et al. 2016). The most recent GCM, which is from the CMIP6 (Eyring et al. 2016), have demonstrated qualitative and quantitative improvements over earlier generations of CMIP phases such as CMIP5 (Stocker et al. 2014; Taylor et al. 2012) and CMIP3 (Solomon et al. 2007), both in the representation of physical processes and the simulated fields as well as higher spatial resolution. The four sets of greenhouse gas emission scenarios called representative concentration pathways (RCPs) of RCP2.6,4.5,6.0 and RCP8.5 of the CMIP5 (Maloney et al. 2014) have been upgraded to shared socio-economic pathways (SSPs) SSP1-2.6, 2-4.5, SSP4-6.0, and SSP5-8.5, respectively. Uncertainty and bias remain large in the GCMs, limiting their applicability in impact studies, and it increases with an increasing number of climate models. Therefore, selecting climate models is vital for regional impact studies. From the large set of existing GCMs with high capability to represent future climate for a particular area is vital for climate impacts studies. Therefore, selection of climate models capable of representing future climate from the large set of existing GCMs is vital for climate impacts studies for a particular area. Therefore, the wide-ranging assessment of climate model performance is essential for the appropriate interpretation of the simulated results. The criteria to be considered on which climate variables are included depends on the impact study goals. For example, a study about the possibility of flood and drought occurrence will most likely consider changes of extremely high and dry rainfall events. In contrast, an assessment of evaporation due to climate change impact will be more concerned with temperature and related data. 
The relevance and applicability of climate models at a local-scale for the study of climate change are limited because the raw GCM output is not capable of representing climate variables of particular regions (S.H Gebrechorkos et al. 2019; Joetzjer et al. 2013; Knutti and Sedláček 2013; Lutz et al. 2013). This is due to their coarser spatial resolution $(>100 \mathrm{~km})$, inappropriate climate model selection approaches, emission scenarios, inaccurate representations of the complex natural interconnections, downscaling approaches, biases and uncertainties of model structures (Legates 2002; Mandal et al. 2019). The spatial resolutions of the raw GCM outputs are very coarse, which makes their direct usage in hydrological models not always recommended (S. H Gebrechorkos et al. 2019). Therefore, to improve the spatial resolution, climate models should be downscaled (Bader et al. 2008) by applying either statistical (Tavakol-Davani et al. 2013) or dynamical downscaling techniques (Chen et al. 2010). Also, bias correction must be performed using appropriate methods to minimize biases (Dixon et al. 2016) before applying the GCM outputs into hydrological models for impact assessment study (Dessu and Melesse 2013; Khan and Koch 2018) and other purposes. Finally, the downscaled climate model outputs will be used as input for the hydrological model to evaluate climate change impact on the hydrological system, especially for the likely change in streamflow, runoff, and other related water balance components.

Uncertainties arise in selecting climate models for impact studies due to large number of climate models. This uncertainty originating from a projected climate model is the primary cause of uncertainty in climate impact studies (Finger et al. 2012). It is more significant than model parameter uncertainty and structural uncertainties of hydrological models (Minville et al. 2008). Therefore, the selection of representative GCM needs strong attention when accompanying a climate change impact study. Different approaches can be used to evaluate the capability and skill of climate models for a specific location and purpose. Model selection can follow a single or multiple criteria approach. Selection of representative climate models can be made mainly based on different approaches: 1) projected changes in mean air temperature and total annual precipitation (Immerzeel et al. 2013; Warszawski et al. 2014) and projected changes in climatic extremes. 2) simulating historical climate performance (Ongoma et al. 2019) for either the means or extremes (Biemans et al. 2013; Pierce et al. 2009; Seager et al. 2007) 3) a combination of the above two approaches, which is called the envelope-based approach (Kaini et al. 2020; Lutz et al. 2016; Sa'adi et al. 2020) 4) taking average outcomes of all available GCM runs (Seager et al. 2007). In general, selecting an appropriate GCM runs highly depends on the purpose and specific location. Identifying an appropriate method for climate model selection is essential. Nevertheless, the aforementioned approaches have benefits and drawbacks that need to be considered during the selection process.

Previous multi-criteria studies conducted on climate model selection for different river basins and regions could not ingest all available ensemble models in the specific repositories during their selection process (Fu et al. 2013; Kaini et al. 2020; Lutz et al. 2016; Sa'adi et al. 2020). For example, Khan and Koch (2018) and Shiru et al. (2021) considered ensemble members who shared the same initial condition from each available GCM, typically the first ensemble member (r1ilp1 of CMIP5) and (r1i111f1 of CMIP6), respectively. Researchers in Ethiopia has implemented climate models to conduct climate change impact in the Awash Basin. Many focused on specific subbasins such as Upper Awash and other watersheds of the basin. However, there is a lack of capacity for consistent projection models and multiple criteria on their procedure to select climate models for a particular purpose. For 
example, Taye et al. (2018) revealed that among 24 GCMs obtained from CMIP5, three GCMs were selected based on performance in capturing historical climate variables. However, models representing the past climate variability of the study area may not describe the future climate projection. This uncertainty of using historical climate models fails to address future Green House Gases (GHG) emissions and different SSPs. The approach inherently assumes that the historical climate remains constant and valid in future projections. Such unguaranteed assumptions may lead to biases in the estimation of future climate and hydrological components. Daba and You (2020) take ensemble means of two climate models selected based on their spatial resolution for the atmospheric variable. The main drawback of applying the average of included GCM runs is that both high-performing and low-performing models are equally weighted. Bekele et al. (2019); Getahun et al. (2020); Tadese et al. (2020) and Tessema et al. (2020) randomly selected GCMs and RCMs from the pool of available climate models. None of the studies considered the mean trend of future projection and the seasonal variability.

This paper attempts to evaluate the CMIP6 GCMs by considering a combination of the two comprehensive approaches, the envelope approach (Kharin et al. 2013; Klein Tank et al. 2009; Min et al. 2009; Min et al. 2011; Park and Min 2019; Seneviratne et al. 2012; Zhang et al. 2011), and the past-performance approach (Biemans et al. 2013) to sort out the most appropriate climate model runs over the UAB. This method consists of three consecutive steps: a) range of projected changes in monthly mean. b) full possible range of projected changes in daily climatic extremes, and c) skill in reproducing past climate. We used 200 climate model runs for SSP4.5 and SSP8.5 for this study. This climate model selection approach is not straightforward; there are different step-wise approaches and handling of several GCMs. Such combined procedures are essential for discovering the incidence and severity of climate extremes and offering a more inclusive valuation than individual assessment criteria. This research comprehensively represents all the projected possible futures, which is essential to address the expected full potential range of climate models under investigation. Besides, GCM selection from the newly released CMIP6 climate models was not conducted over $\mathrm{UAB}$; most future projections and selections were based on CMIP5 models. Therefore, it is necessary to improve the GCM selection and possible climate projection for UAB by adopting the GCMs from CMIP6 under SSP scenarios. Furthermore, we address the limitations of the previous studies by handling several GCM runs and a systematic approach of combined methodology with a narrow uncertainty range, which is a new insight for the study area.

This paper will be the preliminary work to select representative climate models using the advanced envelopebased method in the particular study area. This study aims to: (1) select representative climate model runs for UAB and (2) develop a full future range of climate scenarios based on downscaled and bias-corrected GCM data on UAB.

\section{Study area and data}

\subsection{Study area}

The representative climate model selection and the downscaling process was carried on the UAB, covering an area of $11,575 \mathrm{~km}^{2}$, located in the central part of Ethiopia, which lies within latitudes $8^{\circ} 16^{\prime}$ and $9^{\circ} 18^{\prime} \mathrm{N}$ and longitudes $37^{\circ}$ $57^{\prime}$ and $39^{\circ} 17^{\prime} \mathrm{E}$. UAB is a very important sub-basin of the Awash Basin regarding water resources management as it is the head of the Awash Basin and representative of different climates. The highest and lowest elevation of the 


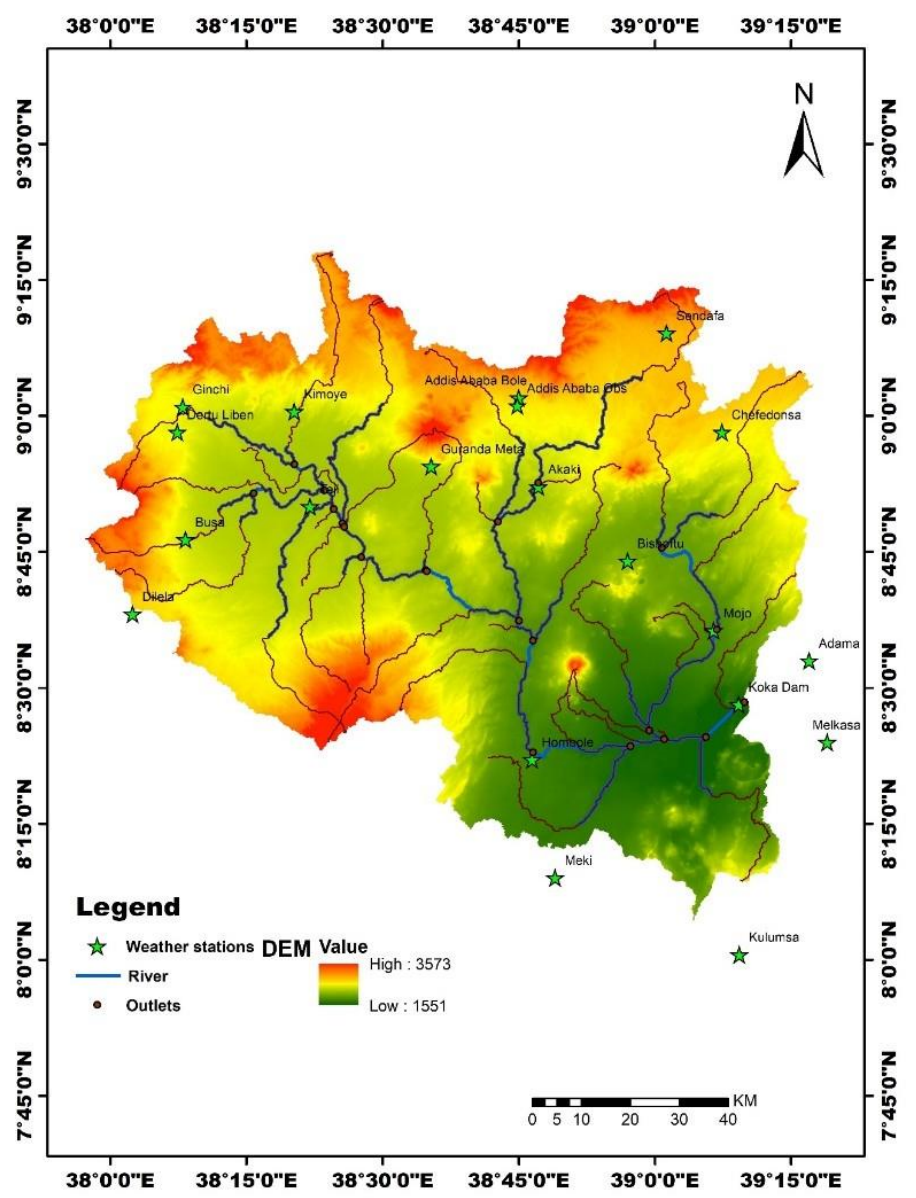

Fig. 1 Study area, the Upper Awash Basin

\subsection{Data}

Daily precipitation, maximum and minimum temperature, were downloaded from the CMIP6 archive (https://esgfnode.1lnl.gov/projects/cmip6). The climate data unavailable on the Earth System Grid Federation website were downloaded from the climate impact archive (https://climate4impact.eu). To fully represent all models from the CMIP6 repository, we download the entire existing ensemble members (symbolized with different realizations) with available monthly and daily data, ensemble members with the two forcing scenarios (SSP4.5 and SSP8.5) for all the variables of interest must have historical and future output extending to 2100. A total of two hundred model runs from the initial pool of GCM runs were included when this simulation was undertaken (October 2020), which is processed in Climate Data Operators (CDO) (Schulzweida et al. 2012) software, developed by Max-Planck Institute for Meteorology (https://code.mpimet.mpg.de/). CDO is a standard climate data processing tool that contains more than 600 command lines. The NCEP-DOE (Kanamitsu et al. 2002) reference data derived based on observed stations were 
used for the base period. The analysis was carried out using 30 years for the historical time frame of (1981-2010), the near future (2031-2060), and the end of the century (2061-2090) period.

\section{Research methods and approach}

The advanced envelope method was adopted in this paper to identify the suitable GCM models for the UAB. This method consists of three interconnected steps, (1) preliminary selection based on a projected range of annual mean temperature and total precipitation sum, (2) changes in climate extremes of daily average precipitation and temperature using the Expert Team on Climate Change Detection and Indices (ETCCDI) and (3) final selection based on models performance to simulate historical climate. This approach covers the skill of a large pool of climate model runs with respect to the NCEP-DOE reference data set. Each independent model run applies directly in the first, second, and third steps rather than average these climate models to produce an ensemble result. A single climate model is insufficient to characterize the complex climatic features. The future projections may vary immensely from wet to drier or hot to cooler future climates. Therefore GCMs are categorized to represent Dry-Cold, Dry-Warm, Wet-Warm, and Wet-Cold corners of the full spectrum. The complete range of likely future climatic circumstances needs to be covered to evaluate the full range of probable climate impact.

\subsection{Initial shortlisting based on changes in mean air temperature and annual precipitation}

As the first step, after resampling all available GCM runs to a common spatial resolution of $1.0^{\circ} \times 1.0^{\circ}$ grid $(\sim 100$ calculated across the UAB. Changes in annual mean temperature $(\Delta T)$ and annual percentile mean of annual precipitation $(\Delta \mathrm{P} \%)$ were calculated with respect to the reference period. The $10^{\text {th }}$ and $90^{\text {th }}$ percentile values of $\Delta \mathrm{P}$ and $\Delta \mathrm{T}$ were calculated, representing the four corners of the seasonal projection of the study area as indicated in Table 1. The models closest to a corner of the spectrum represent the skilled model. Each model distance to the closest corner of the spectrum is calculated using the equation adopted from Lutz et al. (2016). Equation 1 calculates the distance (D) of each model to the closest corner of the spectrum, and the models are then ranked based on the value of D. Finally, five ensemble model runs with the lowest value of $(D)$, are selected from each corner of the spectrum and qualify for the next step of the process.

where $D_{p_{j}^{P}, p_{j}^{T}}$ is the distance of models $(j)^{\prime} s \Delta T$ and $\Delta P\left(P_{j}^{P}\right.$ and $P_{j}^{T}$, respectively) to the corner $(i)^{\prime} s 10^{t h}$ and/or $90^{\text {th }}$ a percentile score of $\Delta T$ and $\Delta P$ for the whole ensemble $\left(P_{j}^{P}\right.$ and $\left.P_{j}^{T}\right)$, respectively.

Table 1 Seasonal projection representing the four corners of climate extremes

\begin{tabular}{|lll|}
\hline$\Delta \mathbf{T}$ & $\Delta \mathbf{P} \%$ & Seasonal Projection \\
\hline $10^{\text {th }}$ & $90^{\text {th }}$ & Cold-Wet $(\mathrm{C}-\mathrm{W})$
\end{tabular}




$$
\begin{array}{lll}
90^{\text {th }} & 10^{\text {th }} & \text { Warm-Dry (W-D) } \\
10^{\text {th }} & 10^{\text {th }} & \text { Cold-Dry (C-D) } \\
90^{\text {th }} & 90^{\text {th }} & \text { Warm-Wet (W-W) }
\end{array}
$$

\subsection{Selection based on changes in climate extremes}

For the qualified models, we evaluated their changes based on climate extremes in this step. The models are subjected to changes in climate extremes relating to temperature and precipitation. The calculations were computed using CDO software for the CMIP6 data sets covering UAB using the same procedure as Sillmann et al. (2013a). Table 2 shows the two climate extremes, each for temperature and precipitation, considered for this study using daily GCM and reference data sets remapped to a common grid of $1^{\circ} \times 1^{\circ}$ resolution. As a set of 27 indices provided by Sillmann et al. (2013a), we have focused only on some of the most relevant extreme temperature and precipitation indicators. Detailed descriptive information and a list of all ETCCDI climate indices can be found on http://etccdi.pacificclimate.org/list 27 indices.shtml. Warm spell duration index (WSDI) and cold spell duration index (CSDI) is considered for the temperature, while consecutive dry day index (CDD) and total precipitation from wet days (R95PTOT) are considered for precipitation indices. R95PTOT and CDD are relevant indicators for rainfall extremes and provide information for proper water management, agricultural management, and assessing flow storage magnitude and drainage. CDD is also an indicator of water stress which affects crop growth and helpful for drought assessment and low flow episodes. WSDI and CSDI are also important indicators of water stress and determine the process of evapotranspiration.

The indices are averaged over the 30 years for the reference data and the two future projections. Subsequently, the percentual changes of the projected period were calculated with respect to the reference period. During the refined selection, skill scores are calculated using the most relevant index for temperature and precipitation for each corner of the spectrum. For example, the models selected for the Dry-Cold corner, CDD and CSDI, are considered, while CDD and WSDI are considered for the Dry-Warm corner. Likewise, for the models selected from the Wet-Warm corner, R95PTOT and WSDI were considered, while R95PTOT and CSDI were considered for the Cold-Wet corner of the spectrum. The five models from each corner are ranked 1 to 5. For example, for the most relevant index for air temperature and precipitation in the Cold-Dry corner, the specific models with the maximum increment in CSDI and CDD, respectively, score five points. In contrast, the model runs with the lowest increment in CSDI, and CDD scores 1 for both temperature and precipitation index rank. Two GCM runs with the highest combined score values were selected for the next step. Therefore the total number of shortlisted model runs is reduced from five to two in each

\begin{tabular}{|c|c|c|}
\hline Meteorological variable & ETCCDI index & Description of the ETCCDI index \\
\hline Precipitation & \begin{tabular}{l|l} 
R95PTOT \\
\end{tabular} & $\begin{array}{l}\text { Precipitation due to extremely wet days (annual total precipitation when } \\
\text { daily rainfall }>95 \text { th percentile) }\end{array}$ \\
\hline
\end{tabular}
corner.

Table 2 Description of ETCCDI indices used for the study 


\begin{tabular}{|l|l|l|}
\hline & CDD & $\begin{array}{l}\text { Consecutive dry days: maximum length of a dry spell when (Precipitation }< \\
1 \mathrm{~mm})\end{array}$ \\
\hline \multirow{3}{*}{ Temperature } & WSDI & $\begin{array}{l}\text { Warm spell duration index: count of days in at least six days where } \\
\text { maximum temperature }(\mathrm{TX})>90 \text { th percentile }\end{array}$ \\
\cline { 2 - 3 } & CSDI & $\begin{array}{l}\text { Cold spell duration index: count of days in at least six days where minimum } \\
\text { temperature }(\mathrm{TN})<10 \text { th percentile }\end{array}$ \\
\hline
\end{tabular}

\subsection{Final selection based on model performance to represent the past climate}

The selected model runs in refined selection (step two) were processed further using a validation step to compare their performance in simulating the past climate using monthly average air temperature and precipitation data. The study area is divided into three subregions; the upper, middle, and lower subregions of UAB. This evaluation is done per subregion for a more detailed regional model selection analysis to avoid omission and underestimations in the entire study area. These subregions are selected bearing in mind that they show more or less similar climatic features. A method adapted from Sánchez et al. (2009) was used for the precipitation skill score calculation. This procedure involves five skill score functions considering all the behavioral aspects of precipitation averaged over the 30-year historical period (1981-2010). The skill score equations are described therein.

$f_{1=1}-\left(\frac{\left|A_{G C M}-A_{N C E P-D O E}\right|}{2 A_{N C E P-D O E}}\right)^{0.5}$

$f_{2=} 1-\left(\frac{\left|A_{G C M}^{+}-A_{N C E P-D O E}^{+}\right|}{2 A_{N C E P-D O E}^{+}}\right)^{0.5}$

$f_{3}=1-\left(\frac{\left|A_{G C M}^{-}-A_{N C E P-D O E}^{-}\right|}{2 A_{N C E P-D O E}^{-}}\right)^{0.5}$

$f_{4=} 1-\left(\frac{\left|\overline{P_{G C M}}-\overline{P_{N C E P-D O E}}\right|}{2 \overline{P_{N C E P-D O E}}}\right)^{0.5}$

$f_{5}=1-\left(\frac{\left|\sigma_{G C M}-\sigma_{N C E P-D O E}\right|}{2 \sigma_{N C E P-D O E}}\right)^{0.5}$

Where $A_{G C M}$ and $A_{N C E P-D O E}$, are areas below the PDFs of the GCMs and reference data, respectively. $A^{+}$and $A^{-}$are areas above and below the $50^{\text {th }}$ percentile, $\mathrm{P}$ is the mean annual precipitation over the given subregion, and $\sigma$ is the standard deviation of the PDF. The distribution is taken into account through the total area below the probability density function (Equation 3). The mean Precipitation (Equation 6) of GCMs and reanalysis are taken in Equation 1 and Equation 4, respectively. Similarly, by calculating the amount of $50^{\text {th }}$ percentile precipitation value of both GCM and reanalysis data, the higher (Equation 4) and lower (Equation 5) precipitation value are accounted for by analyzing amounts below and above the $50^{\text {th }}$ percentile limit, respectively, whereas (Equations 7) the shape of the distribution is defined through the variance. The five skill score functions are multiplied (Equations 8) to get the total skill score of given GCM precipitation per subregion.

Total $_{\text {skill }}^{\text {score }}=\left(f_{1} \cdot f_{2} \cdot f_{3} \cdot f_{4} \cdot f_{5}\right)$

For temperature skill score calculation, the commonly used Taylor diagram approach was applied (Taylor 2005). The approach involves using the Taylor diagram software (https://agrimetsoft.com//taylor_diagram_software) to compute the correlation of air temperature between the reference and GCM model datasets. If a GCM simulates the 
observed data perfectly, the correlation value will be 1 . On the contrary, if a model simulation showed a significant deviation from the observed data, the skill score or correlation will be near zero. The correlation and skill score values for temperature and precipitation, respectively, indicate the relative similarity or deviation between the GCM model and reference data sets.

Where $\mathrm{R}$ is the correlation coefficient between simulated and reanalysis data, $E^{\prime}$ is the centred RMS difference and

$\sigma_{f}^{2}$ and ${\sigma_{r}}^{2}$ are the variances of the simulated and reference data. The average is taken from the control period skill score of temperature and precipitation, and these scores are ranked for the three subregions separately. As a final step, to get the general ranking of each model run, the rank of each subregion is summed, resulting in a ranking for the entire UAB area. The highest-ranked GCM indicates the best performance with the least bias, while the lowest-ranked GCM indicates the worst performance with the largest bias. Based on this ranking, one model qualifies as the best model at every corner.

The multi-criteria method adopted in this study to select the best model runs with the best capability to represent the past and possible future climate for UAB is in line with the techniques proposed by Kim et al. (2020); Lutz et al. (2016); Sánchez et al. (2009) and Sillmann et al. (2013b)

\subsection{Climate data downscaling and bias correction}

There are two methods to downscale raw GCM outputs: dynamical downscaling (DD) and statistical downscaling (SD). The SD develops a statistical relationship between local-scale climate variables and large-scale GCM outputs (S. H Gebrechorkos et al. 2019; Kaini et al. 2020). Besides, SD is simple, requires less resources, and is computationally efficient. It is suitable to achieve spatial downscaling and bias correction of multiple models, and their resolution is higher than DD. Also, they are widely used in different sectors (Brown et al. 2008; Wilby et al. 2002). On the other hand, DD techniques use local physical factors such as topographic features nested within a GCM to produce local or Regional Climate Models (RCMs) at a fine-scale resolution, usually $50 \mathrm{~km}$ (Endris et al. 2013). In addition, it requires many resources and is time-consuming (Trzaska and Schnarr 2014).

After selecting the representative GCMs, the models were downscaled from coarser to a finer spatial resolution using observed data from 20 stations retrieved from the National Meteorological Agency of Ethiopia. This paper used the SD-GCM V2.0 software to statistically downscale the GCMs spanning through the study period of 2031-2060 and 2061-2090. We used three distinct methods of SD approach, the Delta change (Hay et al. 2000), the Quantile Mapping (QM) (Wood et al. 2004), and the Empirical Quantile Mapping (EQM) (Boé et al. 2007). These three approaches have been applied for all selected GCMs. We subjected the models to different efficiency criteria, Pearson Correlation, Spearman and Index of Agreement as performance indicators with respect to observations. This method has been effectively applied in the hydrological application for different purposes (Themeßl et al. 2012). 


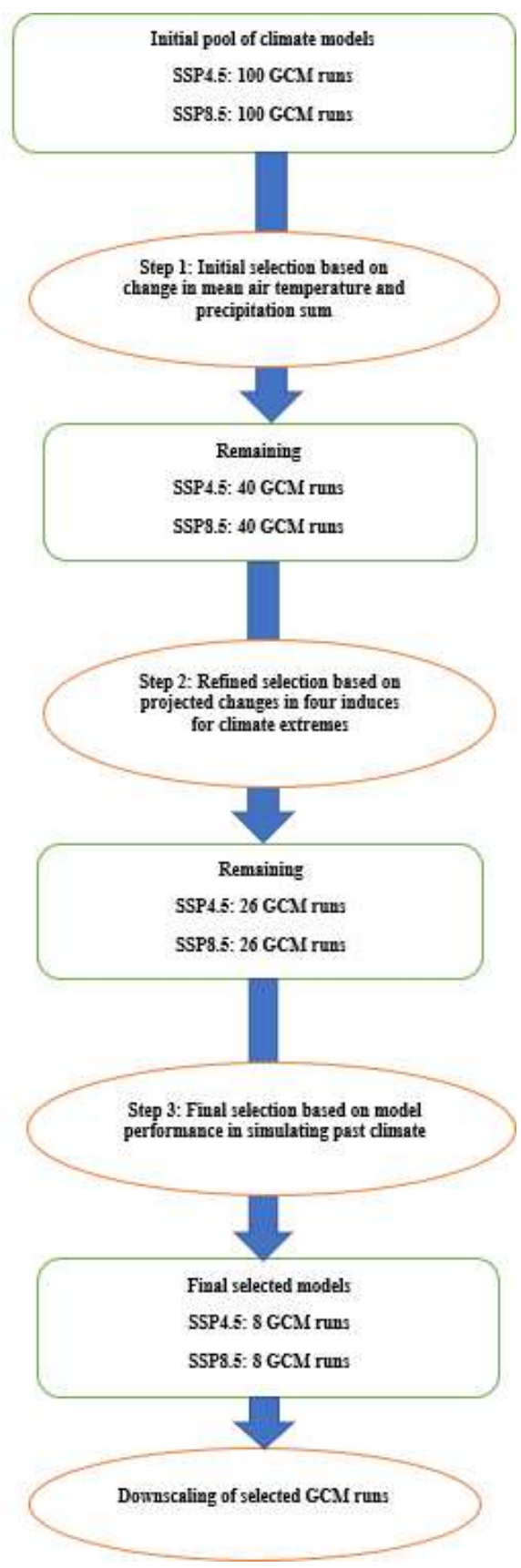

Fig 2. Flow chart showing the steps adopted in this study for climate model selection

\section{Results and discussion}

$293 \quad 4.1$ Climate model selection

294 4.1.1 Climate Models selection based on Changes in Climatic Means (step 1)

296 As described in Section 3.1, the first step is based on projected changes in mean air temperature $(\Delta \mathrm{T})$ and annual

297 precipitation $(\Delta \mathrm{P})$ between future and reference periods, as shown in Supplementary Tables S1-S4. We calculated the 
average annual air temperature and precipitation for the reference dataset and $200 \mathrm{GCM}$ runs over UAB. The historical value of rainfall and the average temperature of the basin was $1225.8 \mathrm{~mm}$ and $16.3^{\circ} \mathrm{C}$, respectively. The $\Delta \mathrm{T}$ projection values of the end of the century (2061-2090) are higher than the mid-century (2031-2060). On the contrary, the change in annual precipitation $(\Delta \mathrm{P})$ projections for the end of the century are less than the mid-century projections in both SSPs of 4.5 and $8.5 . \Delta \mathrm{T}$ and $\Delta \mathrm{P}$ vary from $+1.1{ }^{\circ} \mathrm{C}$ to $+8.0^{\circ} \mathrm{C}$ and $-4.4 \%$ to $+16.7 \%$, respectively, under the mid-term period for SSP4.5. In comparison, SSP8.5 vary from $1.3{ }^{\circ} \mathrm{C}$ to $+8.2{ }^{\circ} \mathrm{C}$ and $-4.6 \%$ to $+17.0 \%$. Similarly, the $\Delta \mathrm{T}$ and $\Delta \mathrm{P}$ vary from $1.6^{\circ} \mathrm{C}$ to $+8.7{ }^{\circ} \mathrm{C}$ and $-4.4 \%$ to $+16.65 \%$, respectively, in the 2061-2090 period for SSP 4.5 . While, for SSP8.5, these ranges are from $2.68{ }^{\circ} \mathrm{C}$ to $+10.45{ }^{\circ} \mathrm{C}$ and $-3.2 \%$ to $+16.71 \%$. The range of $\Delta \mathrm{T}$ and $\Delta \mathrm{P}$ for ensemble models under the SSP8.5 was higher than those under SSP4.5 in the respective durations. We selected the five models closest to each corner of the spectrum, making a total of 20 models for every radiative forcing and study period. The model runs are shown in Figure 3.

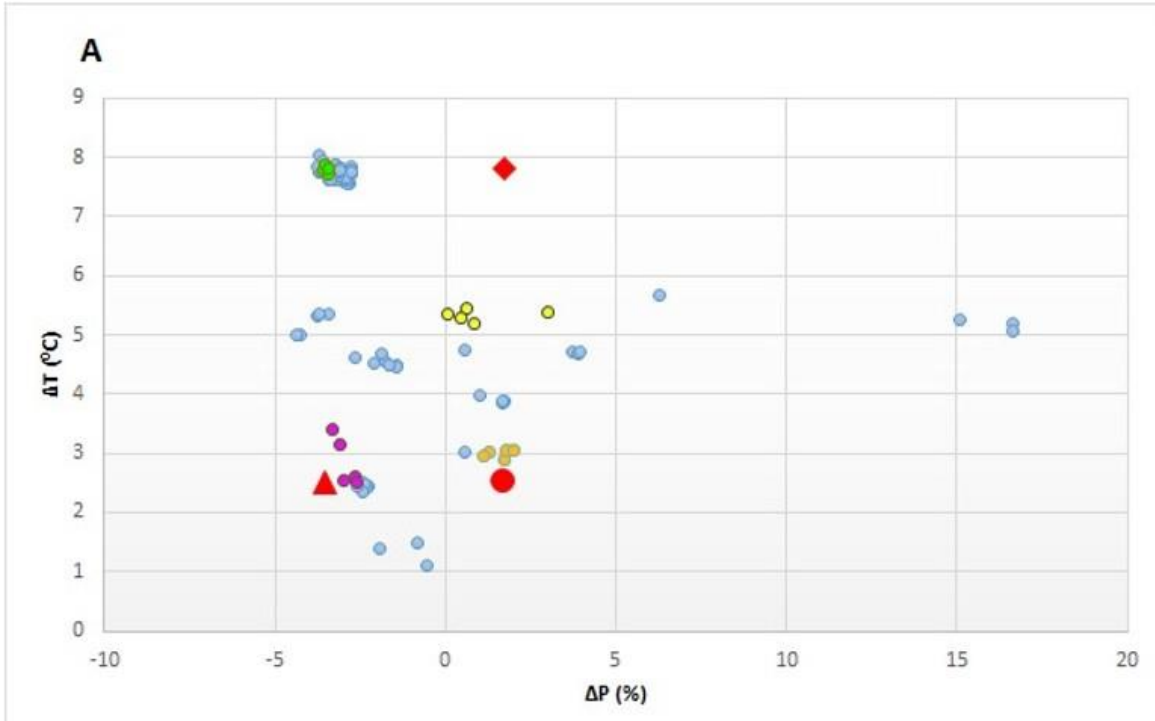




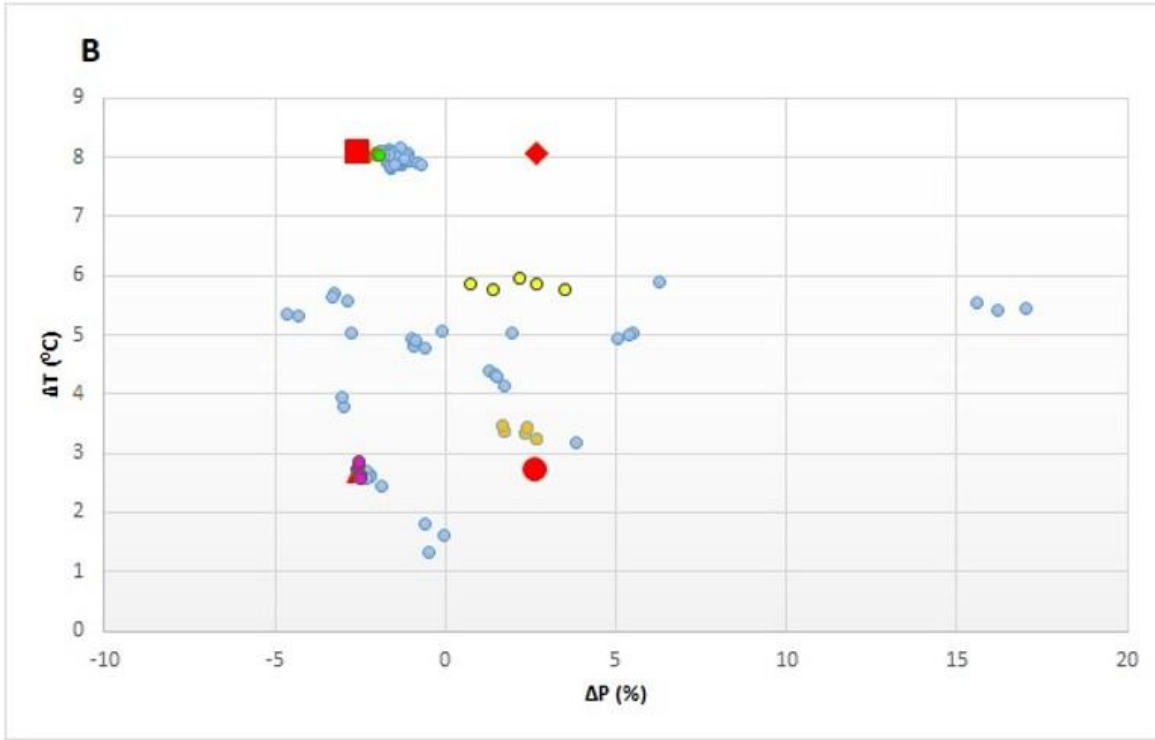

311

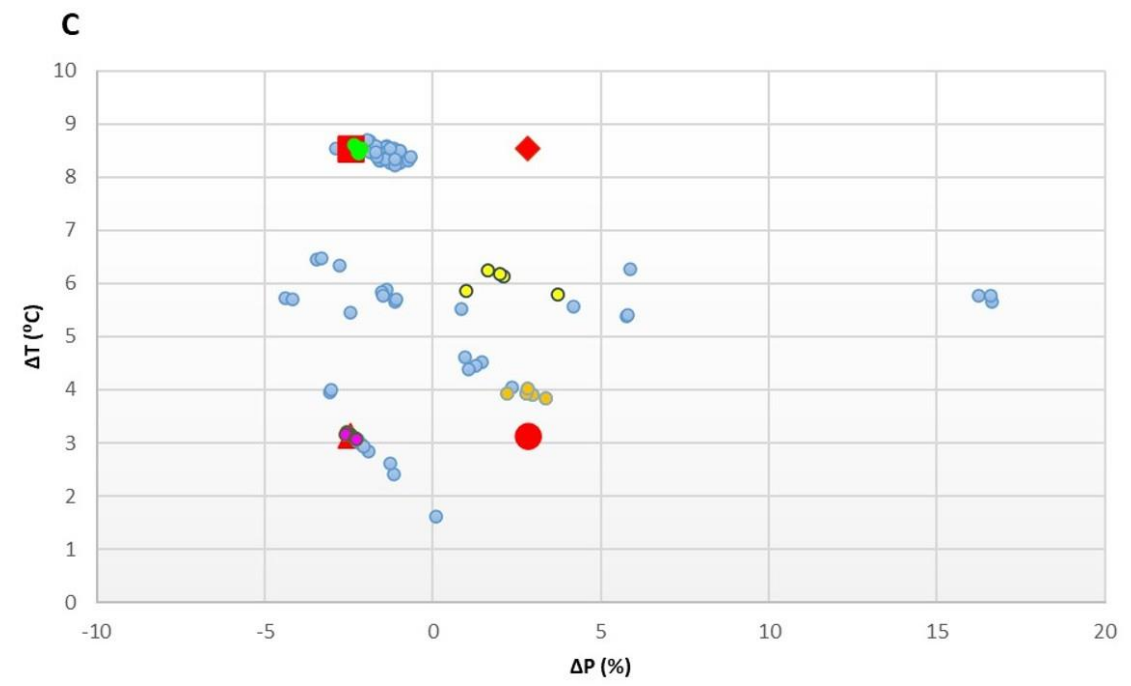




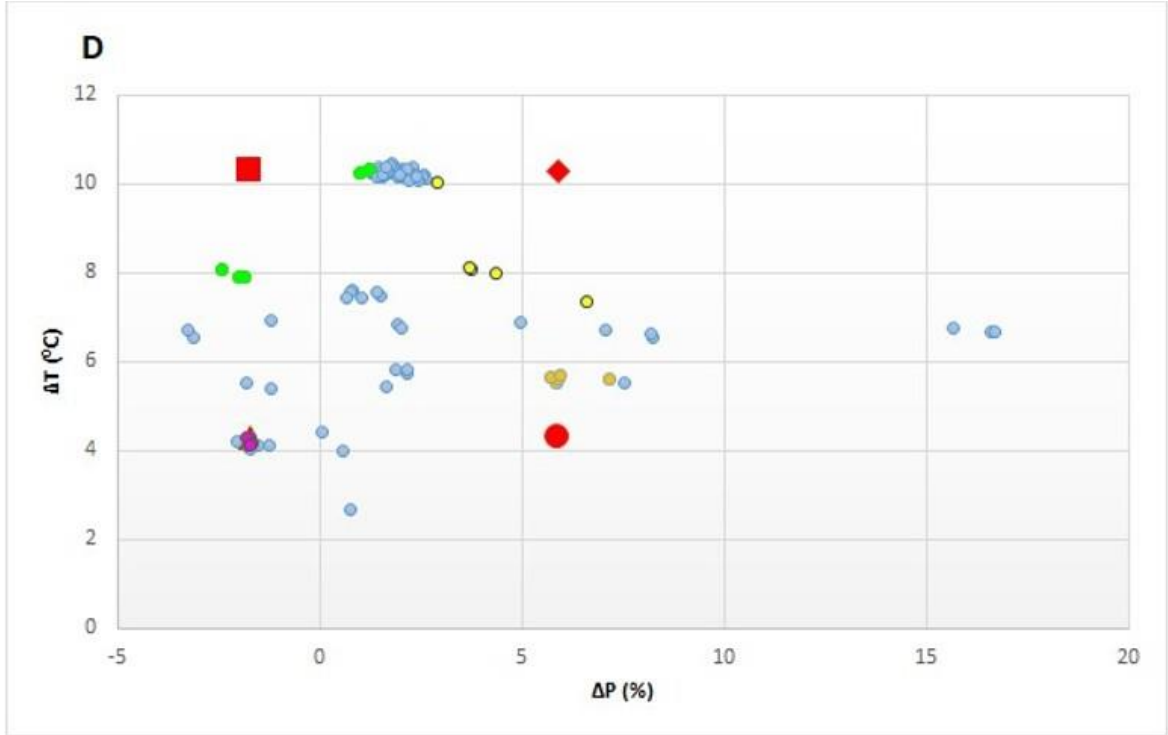

Fig. 3 Projected changes in annual precipitation sum $(\Delta \mathrm{P})$ and mean air temperature $(\Delta \mathrm{T})$ between the Historical period (1980-2010), midcentury (2031-2060), and end-of-century (2061-2090) for all included models (a) and (b) for mid-century considering SSP4.5 and SSP8.5 respectively, (c) and (d) is for the end-of-century considering SSP4.5 and SSP8.5 respectively. Red spots indicate the $10^{\text {th }}$ and $90^{\text {th }}$ values for $\Delta \mathrm{T}$ and $\Delta \mathrm{P} \%$. The model runs selected for Step 2 are marked with the lemon, yellow, pink, and orange colors indicate the selected GCM models for corner one (D-W), two (W-W), three (D-C), and four (W-C), respectively

\subsubsection{Selection based on changes in climatic extremes (Step 2)}

322 The remaining models from step one are subjected to two extreme climate indices for temperature and precipitation during the mid-century and end-of-century periods with respect to the reference data set. Supplementary Table S5-S8 presents the ETCCDI extreme indices of future and historical period, T index rank, $\mathrm{P}$ index rank, and combined score

325 for the entire GCMs selected from step 1. Two models with the highest combined score are selected for each spectrum 326 corner. If two models appear to have the same second combined score, three models were selected for that corner. Tables 3 and 4 show the models with the highest combined score for the study periods painted light gray. 
329 Table 3 Model runs were analysed in step two for mid-century SSP4.5 and SSP8.5. Models selection for Step 3 are marked light gray

\begin{tabular}{|c|c|c|c|c|c|c|c|c|c|c|}
\hline Projection & Models SSP4.5 (2031-2060) & $\operatorname{Pr}$ & $\mathbf{T m}$ & $\Delta \mathrm{CDD} \%$ & $\triangle \mathbf{R 9 5 P T O T \%}$ & $\Delta$ WSDI $\%$ & $\Delta$ CSDI\% & $\begin{array}{l}\text { Tindex } \\
\text { rank }\end{array}$ & $\begin{array}{l}\text { P index } \\
\text { rank }\end{array}$ & $\begin{array}{l}\begin{array}{l}\text { Combined } \\
\text { score }\end{array} \\
\end{array}$ \\
\hline \multirow[t]{5}{*}{ W-D } & CanESM5_r6ilp1f1 & -3.5 & 7.8 & -4.5 & 33.9 & 11810 & -100.0 & 4 & 1 & 2.5 \\
\hline & CanESM5_r25i1p2f1 & -3.6 & 7.8 & 26.3 & 24.5 & 11847 & -100.0 & 5 & 3 & 4 \\
\hline & CanESM5_r20i1p1f1 & -3.5 & 7.9 & 13.7 & 35.4 & 11802 & -100.0 & 3 & 2 & 2.5 \\
\hline & CanESM5_r21i1p2f1 & -3.4 & 7.7 & 29.8 & 37.6 & 11703 & -100.0 & 1 & 4 & 2.5 \\
\hline & CanESM5_r10ilp2f1 & -3.4 & 7.8 & 42.7 & 36.3 & 11704 & -100.0 & 2 & 5 & 3.5 \\
\hline \multirow[t]{5}{*}{ W-W } & INM-CM5-0_rlilp1f1 & 0.6 & 5.5 & -18.5 & -48.0 & 10719 & -100.0 & 5 & 1 & 3 \\
\hline & INM-CM4-8_r1ilp1f1 & 3.0 & 5.4 & -18.2 & -29.5 & 10482 & -100.0 & 4 & 2 & 3 \\
\hline & CESM2_r11ilp1f1 & 0.8 & 5.2 & 26.3 & 51.5 & 9770 & -100.0 & 1 & 5 & 3 \\
\hline & CESM2_r4ilp1f1 & 0.5 & 5.3 & 24.2 & 42.8 & 9949 & -100.0 & 2 & 4 & 3 \\
\hline & CESM2_r10i1p1f1 & 0.1 & 5.4 & 45.6 & 37.7 & 10152 & -100.0 & 3 & 3 & 3 \\
\hline \multirow[t]{5}{*}{ C-D } & MPI-ESM1-2-LR_r4ilp1f1 & -3.0 & 2.5 & 91.8 & -79.2 & 7644 & -61.8 & 5 & 5 & 5 \\
\hline & NESM3_r1i1p1f1 & -3.1 & 3.2 & 60.4 & -54.6 & 9164 & -98.9 & 2 & 4 & 3 \\
\hline & MPI-ESM1-2-LR_r6ilp1f1 & -2.7 & 2.6 & 46.4 & -77.7 & 8142 & -87.8 & 4 & 3 & 3.5 \\
\hline & MPI-ESM1-2-LR_r8ilp1f1 & -2.6 & 2.5 & 40.0 & -77.5 & 7796 & -92.4 & 3 & 1 & 2 \\
\hline & NESM3_r2ilp1f1 & -3.3 & 3.4 & 45.3 & -60.2 & 9640 & -100.0 & 1 & 2 & 1.5 \\
\hline \multirow[t]{5}{*}{$\mathrm{C}-\mathrm{W}$} & IPSL-CM6A-LR_r14ilp1f1 & 1.7 & 2.9 & 42.6 & 21.3 & 5918 & 9.6 & 5 & 3 & 4 \\
\hline & IPSL-CM6A-LR_r3i1p1f1 & 1.8 & 3.0 & 35.9 & 38.1 & 6358 & -31.5 & 1 & 5 & 3 \\
\hline & IPSL-CM6A-LR_r6ilp1f1 & 2.0 & 3.0 & 44.3 & 35.0 & 6307 & 4.6 & 3 & 4 & 3.5 \\
\hline & IPSL-CM6A-LR_r1i1p1f1 & 1.3 & 3.0 & 38.0 & 18.8 & 6174 & 5.0 & 4 & 2 & 3 \\
\hline & IPSL-CM6A-LR_r4i1p1f1 & 1.1 & 3.0 & 46.6 & 16.9 & 6157 & -12.7 & 2 & 1 & 1.5 \\
\hline
\end{tabular}




\begin{tabular}{|c|c|c|c|c|c|c|c|c|c|c|}
\hline Projection & Models SSP8.5 (2031-2060) & Pr & Tm & $\Delta \mathrm{CDD} \%$ & $\triangle$ R95PTOT\% & $\Delta$ WSDI\% & $\Delta \mathrm{CSDI} \%$ & $\begin{array}{l}\text { T index } \\
\text { rank }\end{array}$ & $\begin{array}{l}\text { P index } \\
\text { rank }\end{array}$ & $\begin{array}{l}\text { Combined } \\
\text { score }\end{array}$ \\
\hline \multirow[t]{5}{*}{ W-D } & CanESM5_r22i1p2f1 & -2.8 & 8.2 & 35.8 & 34.5 & 11897 & -100.0 & 5.0 & 5.0 & 5.0 \\
\hline & CanESM5_r18i1p2f1 & -2.3 & 8.0 & 17.1 & 39.6 & 11854 & -100.0 & 2.0 & 3.0 & 2.5 \\
\hline & CanESM5_r5i1p2f1 & -2.1 & 8.1 & 18.5 & 43.7 & 11863 & -100.0 & 4.0 & 4.0 & 4.0 \\
\hline & CanESM5_r12i1p2f1 & -2.0 & 8.0 & 8.4 & 50.4 & 11813 & -100.0 & 1.0 & 2.0 & 1.5 \\
\hline & CanESM5_r20i1p2f1 & -1.9 & 8.0 & -3.3 & 56.2 & 11859 & -100.0 & 3.0 & 1.0 & 2.0 \\
\hline \multirow[t]{5}{*}{ W-W } & CESM2_r10i1p1f1 & 2.2 & 5.9 & 51.6 & 70.2 & 10871 & -100.0 & 3.0 & 3.0 & 3.0 \\
\hline & CESM2_r4i1p1f1 & 2.6 & 5.9 & 48.7 & 72.6 & 10820 & -100.0 & 2.0 & 4.0 & 3.0 \\
\hline & INM-CM4-8_r1i1p1f1 & 3.5 & 5.8 & -23.1 & -24.6 & 10957 & -100.0 & 4.0 & 2.0 & 3.0 \\
\hline & INM-CM5-0_r1i1p1f1 & 1.4 & 5.8 & -9.5 & -36.0 & 11146 & -100.0 & 5.0 & 1.0 & 3.0 \\
\hline & CESM2_r11i1p1f1 & 0.7 & 5.8 & 14.6 & 92.1 & 10803 & -100.0 & 1.0 & 5.0 & 3.0 \\
\hline \multirow[t]{5}{*}{ C-D } & MPI-ESM1-2-LR_r3i1p1f1 & -2.6 & 2.7 & 56.0 & -77.6 & 8320 & -94.0 & 1.0 & 2.0 & 1.5 \\
\hline & MPI-ESM1-2-LR_r6ilp1f1 & -2.6 & 2.8 & 49.7 & -74.3 & 8409 & -92.0 & 2.0 & 1.0 & 1.5 \\
\hline & MPI-ESM1-2-LR_r4i1p1f1 & -2.5 & 2.6 & 60.4 & -77.7 & 8023 & -56.5 & 5.0 & 4.0 & 4.5 \\
\hline & MPI-ESM1-2-LR_r8i1p1f1 & -2.5 & 2.6 & 57.5 & -79.7 & 8040 & -87.6 & 4.0 & 3.0 & 3.5 \\
\hline & MPI-ESM1-2-LR_r5i1p1f1 & -2.5 & 2.9 & 77.8 & -81.7 & 8664 & -91.4 & 3.0 & 5.0 & 4.0 \\
\hline \multirow[t]{5}{*}{$\mathrm{C}-\mathrm{W}$} & IPSL-CM6A-LR_r1i1p1f1 & 2.7 & 3.2 & 29.9 & 56.9 & 6849 & -26.6 & 5.0 & 5.0 & 5.0 \\
\hline & IPSL-CM6A-LR_r4i1p1f1 & 2.3 & 3.3 & 34.9 & 31.1 & 7140 & -59.8 & 1.0 & 3.0 & 2.0 \\
\hline & IPSL-CM6A-LR_r14i1p1f1 & 2.4 & 3.4 & 24.9 & 38.3 & 7301 & -57.1 & 2.0 & 4.0 & 3.0 \\
\hline & IPSL-CM6A-LR_r2i1p1f1 & 1.7 & 3.4 & 40.6 & 22.0 & 7265 & -56.3 & 3.0 & 1.0 & 2.0 \\
\hline & IPSL-CM6A-LR_r6ilp1f1 & 1.7 & 3.5 & 51.3 & 29.4 & 7470 & -52.0 & 4.0 & 2.0 & 3.0 \\
\hline
\end{tabular}


Table 4 Model runs were analyzed in step two for end-century SSP4.5 and SSP8.5. Models selection for Step 3 are marked light gray

\begin{tabular}{|c|c|c|c|c|c|c|c|c|c|c|}
\hline Projection & Models SSP4.5 (2061-2090) & Pr & $\mathbf{T m}$ & $\Delta \mathrm{CDD} \%$ & $\Delta$ R95Ptot $\%$ & $\Delta$ WSDI $\%$ & $\Delta \mathrm{CSDI} \%$ & $\begin{array}{l}\text { T index } \\
\text { rank }\end{array}$ & $\begin{array}{l}\text { P index } \\
\text { rank }\end{array}$ & $\begin{array}{l}\text { Combined } \\
\text { score }\end{array}$ \\
\hline \multirow[t]{5}{*}{ W-D } & CanESM5_r16i1p2f1 & -2.4 & 8.6 & 13.1 & 53.8 & 11972 & -100 & 2 & 4 & 3 \\
\hline & CanESM5_r7i1p2f1 & -2.3 & 8.6 & 6.2 & 55.9 & 11977 & -100 & 4 & 2 & 3 \\
\hline & CanESM5_r18i1p2f1 & -2.2 & 8.5 & -7.2 & 62.2 & 11975 & -100 & 3 & 1 & 2 \\
\hline & CanESM5_r10i1p2f1 & -2.2 & 8.5 & 9.9 & 57.4 & 11923 & -100 & 1 & 3 & 2 \\
\hline & CanESM5_r4i1p2f1 & -2.1 & 8.6 & 30.4 & 55.1 & 11991 & -100 & 5 & 5 & 5 \\
\hline \multirow[t]{5}{*}{ W-W } & CESM2_r10i1p1f1 & 2.1 & 6.1 & 19.2 & 81.8 & 11174 & -100 & 2 & 5 & 4 \\
\hline & CESM2_r11i1p1f1 & 2.0 & 6.2 & 12.3 & 81.2 & 11297 & -100 & 4 & 4 & 4 \\
\hline & CESM2_r4i1p1f1 & 1.6 & 6.3 & 13.7 & 75.0 & 11410 & -100 & 5 & 3 & 4 \\
\hline & INM-CM4-8_r1i1p1f1 & 3.7 & 5.8 & -26.8 & -18.7 & 11048 & -100 & 1 & 2 & 2 \\
\hline & INM-CM5-0_r1ilp1f1 & 1.0 & 5.9 & -26.1 & -39.1 & 11224 & -100 & 3 & 1 & 2 \\
\hline \multirow[t]{5}{*}{ C-D } & MPI-ESM1-2-LR_r1i1p1f1 & -2.4 & 3.2 & 24.0 & -77.9 & 9327 & -99 & 1 & 1 & 1 \\
\hline & MPI-ESM1-2-LR_r2i1p1f1 & -2.6 & 3.2 & 44.3 & -76.4 & 9375 & -98 & 2 & 3 & 3 \\
\hline & MPI-ESM1-2-LR_r6ilp1f1 & -2.6 & 3.2 & 63.0 & -79.2 & 9372 & -96 & 4 & 5 & 5 \\
\hline & MPI-ESM1-2-LR_r5i1p1f1 & -2.3 & 3.1 & 58.5 & -77.3 & 9200 & -94 & 5 & 4 & 5 \\
\hline & MPI-ESM1-2-LR_r9i1p1f1 & -2.3 & 3.1 & 41.8 & -82.0 & 9224 & -97 & 3 & 2 & 3 \\
\hline \multirow[t]{5}{*}{$\mathrm{C}-\mathrm{W}$} & IPSL-CM6A-LR_r2i1p1f1 & 3.0 & 3.9 & 29.8 & 50.0 & 8577 & -96 & 2 & 5 & 4 \\
\hline & IPSL-CM6A-LR_r14i1p1f1 & 2.8 & 3.9 & 27.6 & 45.3 & 8522 & -88 & 4 & 3 & 4 \\
\hline & IPSL-CM6A-LR_r1i1p1f1 & 2.8 & 4.0 & 16.5 & 40.8 & 8706 & -96 & 2 & 2 & 2 \\
\hline & IPSL-CM6A-LR_r4ilp1f1 & 3.4 & 3.8 & 41.6 & 49.6 & 8417 & -89 & 3 & 4 & 4 \\
\hline & IPSL-CM6A-LR_r3i1p1f1 & 2.2 & 3.9 & 23.6 & 37.7 & 8588 & -86 & 5 & 1 & 3 \\
\hline
\end{tabular}




\begin{tabular}{|c|c|c|c|c|c|c|c|c|c|c|}
\hline Projection & Models SSP8.5 (2061-2090) & Pr & $\mathbf{T m}$ & $\Delta \mathrm{CDD} \%$ & $\triangle$ R95РTOT\% & $\Delta$ WSDI $\%$ & $\Delta \mathrm{CSDI} \%$ & $\begin{array}{l}T \text { index } \\
\text { rank }\end{array}$ & $\begin{array}{l}\text { P index } \\
\text { rank }\end{array}$ & $\begin{array}{l}\text { Combined } \\
\text { score }\end{array}$ \\
\hline \multirow[t]{5}{*}{ W-D } & ACCESS-CM2_r2i1p1f1 & -2.4 & 8.1 & 23.9 & -1.1 & 12111 & -100 & 4 & 5 & 4.5 \\
\hline & ACCESS-CM2_r1i1p1f1 & -1.8 & 7.9 & 19.0 & 1.1 & 12109 & -100 & 2 & 4 & 3 \\
\hline & ACCESS-CM2_r3i1p1f1 & -2.0 & 7.9 & 8.8 & -4.5 & 12115 & -100 & 5 & 3 & 4 \\
\hline & CanESM5_r24i1p2f1 & 1.0 & 10.3 & -15.5 & 88.4 & 12110 & -100 & 3 & 2 & 2.5 \\
\hline & CanESM5_r6i1p2f1 & 1.3 & 10.3 & -18.1 & 91.4 & 12102 & -100 & 1 & 1 & 1 \\
\hline \multirow[t]{5}{*}{$\mathrm{W}-\mathrm{W}$} & CESM2_r4ilp1f1 & 4.4 & 8.0 & 18.8 & 102.9 & 12040 & -100 & 2 & 5 & 3.5 \\
\hline & MIROC-ES2L_r1i1p1f2 & 6.6 & 7.4 & -27.1 & 15.4 & 12024 & -100 & 1 & 1 & 1 \\
\hline & CanESM5_r1i1p2f1 & 2.9 & 10.0 & 29.8 & 17.9 & 12110 & -100 & 5 & 2 & 3.5 \\
\hline & CESM2_r11i1p1f1 & 3.7 & 8.1 & 8.5 & 87.7 & 12045 & -100 & 3 & 3 & 3 \\
\hline & CESM2_r10i1p1f1 & 3.7 & 8.1 & -2.1 & 95.1 & 12049 & -100 & 4 & 4 & 4 \\
\hline \multirow[t]{5}{*}{ C-D } & MPI-ESM1-2-LR_r6ilp1f1 & -1.7 & 4.3 & 57.0 & -78.5 & 11046 & -100 & 1 & 5 & 3 \\
\hline & MPI-ESM1-2-LR_r4i1p1f1 & -1.8 & 4.3 & 53.4 & -75.5 & 11168 & -100 & 1 & 3 & 2 \\
\hline & MPI-ESM1-2-LR_r8i1p1f1 & -1.7 & 4.2 & 52.1 & -71.3 & 11042 & -100 & 1 & 2 & 1.5 \\
\hline & MPI-ESM1-2-LR_r10i1p1f1 & -1.8 & 4.1 & 47.5 & -73.7 & 10998 & -100 & 1 & 1 & 1 \\
\hline & MPI-ESM1-2-LR_r7i1p1f1 & -1.7 & 4.1 & 54.7 & -75.8 & 10998 & -100 & 1 & 4 & 2.5 \\
\hline \multirow[t]{5}{*}{$\mathrm{C}-\mathrm{W}$} & IPSL-CM6A-LR_r2i1p1f1 & 5.9 & 5.5 & 29.8 & 76.9 & 10980 & -99 & 4 & 2 & 3 \\
\hline & IPSL-CM6A-LR_r1i1p1f1 & 5.9 & 5.6 & 22.9 & 92.0 & 10989 & -99 & 4 & 4 & 4 \\
\hline & IPSL-CM6A-LR_r14i1p1f1 & 5.7 & 5.6 & 27.4 & 92.7 & 11047 & -100 & 2 & 5 & 3.5 \\
\hline & IPSL-CM6A-LR_r3i1p1f1 & 6.0 & 5.7 & 11.9 & 88.7 & 11059 & -98 & 5 & 3 & 4 \\
\hline & IPSL-CM6A-LR_r6i1p1f1 & 7.2 & 5.6 & 3.5 & 88.7 & 11017 & -100 & 2 & 3 & 2.5 \\
\hline
\end{tabular}


This procedure of calculating a combined score based on the ranking of indices value can result in the situation whereby GCM runs with the highest value in one of the ETCCDI indices are not selected due to the lowest change in another ETCCDI indices. For example, in the W-C corner, considering the mid-century period for SSP4.5, the IPSL-CM6A-LR_r3i1p1f1 model is not selected while it projects the largest changes in R95PTOT. Similarly, the W-W corner for the SSP8.5 CESM2_r11i1p1f1 model is not selected, although it projects the higher changes in R95PTOT in the end-century period. From the C-W corner, IPSL-CM6A-LR_r14i1p1f1 is not selected even though it projects the largest changes in R95PTOT. The refined selection based on the changes in four ETCCDI indices between the base and future period is provided in Supplementary Table S1- S8.

It is worth mentioning that the model with a large or low change of mean precipitation or temperature also coincides with the highest change in the relevant extreme indices. For example, CanESM5_r22i1p2f1 considering SSP8.5 projected the slightest change in $\Delta \mathrm{T}\left(8.2^{\circ} \mathrm{C}\right)$ and $\Delta \mathrm{P}(-2.75 \%)$ in the W-D corner for the middle-term period, which also projected the largest increase in WSDI (11897\%) and CDD (35.8\%), also the largest decrease in CSDI and R95PTOT. CDD increases in mid-century $-18.5 \%$ to $+91.8 \%$ and $-23.1 \%$ to $+77.8 \%$ under SSP4.5 and SSP 8.5 , respectively. Similarly, at the end-century, CDD is projected to increase from $-26.8 \%$ to $+63.0 \%$ and $-27.1 \%$ to $+57.0 \%$, considering SSP4.5 and SSP8.5, respectively. The models estimated an increase in R95PTOT from -79.2\% to $+51.5 \%$ and $-81.7 \%$ to $+92.1 \%$ for SSP4.5 and SSP8.5 respectively, in the mid-century, but from $-82.0 \%$ to $+81.8 \%$ and $-78.5 \%$ to $+102.9 \%$ for the respective SSP in the end-century. An increase in R95PTOT forecasts more precipitation in the coming periods. The WSDI is projected to increase for all scenarios and periods, and it is estimated at $6849 \%$ to $11897 \%$ for SSP 4.5 and $6849 \%$ to $12,115 \%$ for SSP 8.5 in the mid and end century, respectively.

Also, an increase in WSDI forecasts an increase in maximum temperature in the future compared to the historical period. Increasing trends of WSDI indicate a warmer future, which may affect water resources management, natural ecosystems, and human health. The increase in CSDI projected $-100.0 \%$ to $9.6 \%$ and $-100.0 \%$ to $-26.6 \%$ for SSP4.5 and SSP8.5, respectively, during mid-century and an increase from - $100 \%$ to $-86 \%$ and $-100 \%$ to $-98 \%$ in the end-century for the respective SSPs. Generally, the four selected climate extreme indices found an increased trajectory in the mid and end of the $21^{\text {st }}$ century. Severe climate extremes such as El Niño may frequently occur in the coming decades, resulting in a significant loss of livestock, crop failure, and serious economic impacts. The increase in climate extremes that highly influence climate variability could increase the region susceptibility to drought.

\subsubsection{Final selection based on models past performance (Step 3)}

Model validation based on past performance to the reference data set is the final model selection step as shown in Table 7. Skill scores for precipitation and temperature in the three subregions are shown in Table 5. And Table 6 shows the precipitation and temperature skill scores remaining from step two for each sub-region and the combined or general score. The final selection of models is based on the lowest combined bias score or performance of the GCM to the reference data. Based on the mentioned multi-criteria approach to select capable climate models, we select limited climate models with the appropriate performance to represent the possible future climate projection of UAB.

381 Therefore, the final selected four GCM models with different ensemble members code " $r$ " (realizations) " $i$ " 
382 (initialization methods), " $p$ " (physics details) " $f$ " (forcing) are namely, CanESM5, MPI-ESM1-2-LR, IPSL-CM6ALR, INM-CM4-8, and ACCESS-CM2.

Table 5 Skill scores for model runs remaining after Step 2. Skill scores are calculated for precipitation and temperature for three

\begin{tabular}{|c|c|c|c|c|c|c|c|c|}
\hline \multirow[b]{2}{*}{ SSP/Year } & \multirow[b]{2}{*}{ Projections } & \multirow[b]{2}{*}{ GCM runs } & \multicolumn{3}{|c|}{ Precipitation SS } & \multicolumn{3}{|c|}{ Temperature SS } \\
\hline & & & LR & MR & UR & LR & MR & UR \\
\hline \multirow[t]{8}{*}{ SSP4.5/2031-2060 } & W-D & CanESM5_r25i1p2f1 & 0.07 & 0.13 & 0.07 & 0.63 & 0.73 & 0.66 \\
\hline & & CanESM5_r10i1p2f1 & 0.08 & 0.15 & 0.07 & 0.57 & 0.68 & 0.49 \\
\hline & $\mathrm{W}-\mathrm{W}$ & INM-CM5-0_r1i1p1f1 & 0.31 & 0.41 & 0.15 & 0.79 & 0.65 & 0.79 \\
\hline & & INM-CM4-8_r1i1p1f1 & 0.61 & 0.68 & 0.18 & 0.76 & 0.53 & 0.77 \\
\hline & C-D & MPI-ESM1-2-LR_r4i1p1f1 & 0.10 & 0.10 & 0.05 & 0.64 & 0.58 & 0.66 \\
\hline & & MPI-ESM1-2-LR_r6i1p1f1 & 0.11 & 0.09 & 0.06 & 0.71 & 0.66 & 0.70 \\
\hline & $\mathrm{C}-\mathrm{W}$ & IPSL-CM6A-LR_r14i1p1f1 & 0.28 & 0.28 & 0.11 & 0.73 & 0.69 & 0.70 \\
\hline & & IPSL-CM6A-LR_r6i1p1f1 & 0.24 & 0.20 & 0.09 & 0.74 & 0.74 & 0.73 \\
\hline \multirow[t]{13}{*}{ SSP4.5/2061-2090 } & W-D & CanESM5_r16i1p2f1 & 0.08 & 0.13 & 0.07 & 0.60 & 0.70 & 0.65 \\
\hline & & CanESM5_r7i1p2f1 & 0.08 & 0.15 & 0.07 & 0.58 & 0.70 & 0.65 \\
\hline & & CanESM5_r4i1p2f1 & 0.08 & 0.15 & 0.08 & 0.58 & 0.69 & 0.64 \\
\hline & $\mathrm{W}-\mathrm{W}$ & INM-CM4-8_r1i1p1f1 & 0.61 & 0.68 & 0.18 & 0.77 & 0.53 & 0.77 \\
\hline & & INM-CM5-0_r1i1p1f1 & 0.31 & 0.41 & 0.15 & 0.79 & 0.65 & 0.79 \\
\hline & C-D & MPI-ESM1-2-LR_r2i1p1f1 & 0.13 & 0.10 & 0.05 & 0.69 & 0.67 & 0.72 \\
\hline & & MPI-ESM1-2-LR_r6i1p1f1 & 0.11 & 0.09 & 0.06 & 0.71 & 0.66 & 0.70 \\
\hline & & MPI-ESM1-2-LR_r5i1p1f1 & 0.10 & 0.09 & 0.05 & 0.70 & 0.68 & 0.72 \\
\hline & & MPI-ESM1-2-LR_r9i1p1f1 & 0.11 & 0.09 & 0.05 & 0.60 & 0.62 & 0.52 \\
\hline & $\mathrm{C}-\mathrm{W}$ & IPSL-CM6A-LR_r2i1p1f1 & 0.37 & 0.29 & 0.10 & 0.74 & 0.72 & 0.72 \\
\hline & & IPSL-CM6A-LR_r14i1p1f1 & 0.28 & 0.28 & 0.11 & 0.73 & 0.69 & 0.70 \\
\hline & & IPSL-CM6A-LR_r4i1p1f1 & 0.36 & 0.27 & 0.10 & 0.75 & 0.74 & 0.73 \\
\hline & & IPSL-CM6A-LR_r3i1p1f1 & 0.33 & 0.25 & 0.09 & 0.72 & 0.70 & 0.71 \\
\hline \multirow{8}{*}{$\begin{array}{l}\text { SSP8.5/2031- } \\
2060)\end{array}$} & W-D & CanESM5_r22i1p2f1 & 0.08 & 0.13 & 0.07 & 0.58 & 0.69 & 0.64 \\
\hline & & CanESM5_r5i1p2f1 & 0.07 & 0.12 & 0.07 & 0.59 & 0.69 & 0.63 \\
\hline & $\mathrm{W}-\mathrm{W}$ & INM-CM4-8_r1i1p1f1 & 0.61 & 0.68 & 0.18 & 0.76 & 0.53 & 0.77 \\
\hline & & INM-CM5-0_r1i1p1f1 & 0.31 & 0.41 & 0.15 & 0.79 & 0.65 & 0.79 \\
\hline & C-D & MPI-ESM1-2-LR_r4i1p1f1 & 0.10 & 0.10 & 0.05 & 0.64 & 0.58 & 0.66 \\
\hline & & MPI-ESM1-2-LR_r5i1p1f1 & 0.10 & 0.09 & 0.05 & 0.70 & 0.68 & 0.72 \\
\hline & C-W & IPSL-CM6A-LR_r1i1p1f1 & 0.38 & 0.30 & 0.10 & 0.68 & 0.72 & 0.57 \\
\hline & & IPSL-CM6A-LR_r6i1p1f1 & 0.24 & 0.20 & 0.09 & 0.74 & 0.74 & 0.73 \\
\hline \multirow[t]{7}{*}{ SSP8.5/2060-2090 } & W-D & ACCESS-CM2_r2i1p1f1 & 0.10 & 0.08 & 0.04 & 0.74 & 0.77 & 0.73 \\
\hline & & ACCESS-CM2_r3i1p1f1 & 0.11 & 0.09 & 0.04 & 0.72 & 0.75 & 0.73 \\
\hline & $\mathrm{W}-\mathrm{W}$ & CanESM5_r1i1p2f1 & 0.08 & 0.13 & 0.07 & 0.52 & 0.47 & 0.62 \\
\hline & C-D & MPI-ESM1-2-LR_r6i1p1f1 & 0.11 & 0.09 & 0.06 & 0.71 & 0.66 & 0.70 \\
\hline & & MPI-ESM1-2-LR_r7i1p1f1 & 0.12 & 0.10 & 0.06 & 0.66 & 0.61 & 0.68 \\
\hline & $\mathrm{C}-\mathrm{W}$ & IPSL-CM6A-LR_r1i1p1f1 & 0.38 & 0.30 & 0.10 & 0.68 & 0.72 & 0.57 \\
\hline & & IPSL-CM6A-LR_r3i1p1f1 & 0.33 & 0.25 & 0.09 & 0.72 & 0.70 & 0.71 \\
\hline
\end{tabular}


LR; Lower region, MR; middle region, UR; Upper region, SS; Skill scores

Under SSP4.5 during the mid-century, CanESM5_r25i1p2f1, INM-CM4-8_r1i1p1f1, MPI-ESM1-2LR_r6i1p1f1, IPSL-CM6A-LR_r14i1p1f1 show a smallest General Rank (GR) values, for W-D, W-W, C-D, C-W corners respectively, indicating their high performance in simulating past climate. Similarly, CanESM5_r7i1p2f1, INM-CM4-8_r1i1p1f1, MPI-ESM1-2-LR_r5i1p1f1, IPSL-CM6A-LR_r4i1p1f1 are the selected models considering SSP4.5 during the 2061-2090 period. CanESM5_r22i1p2f1, INM-CM4-8_r1i1p1f1, MPI-ESM1-2-LR_r5i1p1f1, IPSL-CM6A-LR_r6i1p1f1, ACCESS-CM2_r2i1p1f1, CanESM5_r1i1p2f1, MPI-ESM1-2-LR_r6i1p1f1, and IPSLCM6A-LR_r3i1p1f1 have good performance in simulating the past climate under SSP8.5 during mid and end century. Overall, 16 most suitable GCM models were selected for predicting the future precipitation and temperature pattern in the UAB.

This method of GCM selection will neglect those models that have good skills for certain subregions. For example, under SSP4.5, CanESM5_r4i1p2f1 was selected for the W-D corner with the highest combined score value (5) in step two but was not selected in the final step due to lack of performance in simulating the past climate. The model CanESM5_r7i1p2f1 was selected as it has a better performance in past simulations with the lowest bias score. Finally, MPI-ESM1-2-LR_r6i1p1f1, INM-CM4-8_r1i1p1f1 and MPI-ESM1-2-LR_r5i1p1f1) showed a good performance and are selected for both forcing scenarios.

Table 6 Ranking of the GCM runs for the three subdomains

\begin{tabular}{|c|c|c|c|c|c|c|c|}
\hline \multirow[t]{2}{*}{ SSP /Year } & \multirow[t]{2}{*}{ Projection } & \multirow[t]{2}{*}{ GCM runs } & \multicolumn{3}{|c|}{ Rank per subdomain } & \multirow[t]{2}{*}{ Total } & \multirow[t]{2}{*}{ General rank } \\
\hline & & & LR & MR & UR & & \\
\hline \multirow[t]{8}{*}{ SSP4.5/2031-2060 } & W-D & CanESM5_r25i1p2f1 & 25 & 18 & 24 & 67 & 24 \\
\hline & & CanESM5_r10i1p2f1 & 32 & 23 & 36 & 91 & 33 \\
\hline & $\mathrm{W}-\mathrm{W}$ & INM-CM5-0_r1i1p1f1 & 5 & 4 & 4 & 13 & 4 \\
\hline & & INM-CM4-8_r1i1p1f1 & 2 & 1 & 1 & 4 & 2 \\
\hline & C-D & MPI-ESM1-2-LR_r4i1p1f1 & 22 & 34 & 27 & 83 & 29 \\
\hline & & MPI-ESM1-2-LR_r6i1p1f1 & 17 & 29 & 20 & 66 & 21 \\
\hline & $\mathrm{C}-\mathrm{W}$ & IPSL-CM6A-LR_r14i1p1f1 & 11 & 11 & 11 & 33 & 9 \\
\hline & & IPSL-CM6A-LR_r6i1p1f1 & 13 & 15 & 9 & 37 & 12 \\
\hline \multirow[t]{13}{*}{ SSP4.5/2060-2090 } & W-D & CanESM5_r16i1p2f1 & 27 & 22 & 29 & 78 & 27 \\
\hline & & CanESM5_r7i1p2f1 & 29 & 19 & 25 & 73 & 25 \\
\hline & & CanESM5_r4i1p2f1 & 30 & 21 & 26 & 77 & 26 \\
\hline & $\mathrm{W}-\mathrm{W}$ & INM-CM4-8_r1i1p1f1 & 1 & 1 & 1 & 3 & 1 \\
\hline & & INM-CM5-0_r1i1p1f1 & 5 & 4 & 4 & 13 & 4 \\
\hline & C-D & MPI-ESM1-2-LR_r2i1p1f1 & 19 & 28 & 17 & 64 & 20 \\
\hline & & MPI-ESM1-2-LR_r6i1p1f1 & 17 & 29 & 20 & 66 & 21 \\
\hline & & MPI-ESM1-2-LR_r5i1p1f1 & 20 & 26 & 15 & 61 & 18 \\
\hline & & MPI-ESM1-2-LR_r9i1p1f1 & 24 & 32 & 35 & 91 & 33 \\
\hline & $\mathrm{C}-\mathrm{W}$ & IPSL-CM6A-LR_r2i1p1f1 & 8 & 9 & 8 & 25 & 8 \\
\hline & & IPSL-CM6A-LR_r14i1p1f1 & 11 & 11 & 11 & 33 & 9 \\
\hline & & IPSL-CM6A-LR_r4i1p1f1 & 4 & 10 & 7 & 21 & 7 \\
\hline & & IPSL-CM6A-LR_r3i1p1f1 & 10 & 13 & 13 & 36 & 11 \\
\hline
\end{tabular}




\begin{tabular}{|c|c|c|c|c|c|c|c|}
\hline \multirow[t]{8}{*}{ SSP8.5/2031-2060 } & W-D & CanESM5_r22i1p2f1 & 28 & 24 & 30 & 82 & 28 \\
\hline & & CanESM5_r5i1p2f1 & 31 & 25 & 31 & 87 & 32 \\
\hline & W-W & INM-CM4-8_r1i1p1f1 & 2 & 1 & 1 & 4 & 2 \\
\hline & & INM-CM5-0_r1i1p1f1 & 5 & 4 & 4 & 13 & 4 \\
\hline & C-D & MPI-ESM1-2-LR_r4i1p1f1 & 22 & 34 & 27 & 83 & 29 \\
\hline & & MPI-ESM1-2-LR_r5i1p1f1 & 20 & 26 & 15 & 61 & 18 \\
\hline & $\mathrm{C}-\mathrm{W}$ & IPSL-CM6A-LR_r1i1p1f1 & 9 & 7 & 33 & 49 & 14 \\
\hline & & IPSL-CM6A-LR_r6i1p1f1 & 13 & 15 & 9 & 37 & 12 \\
\hline \multirow[t]{7}{*}{ SSP8.5/2010-2090 } & W-D & ACCESS-CM2_r2i1p1f1 & 15 & 17 & 19 & 51 & 15 \\
\hline & & ACCESS-CM2_r3i1p1f1 & 16 & 20 & 18 & 54 & 16 \\
\hline & W-W & CanESM5_r1i1p2f1 & 33 & 36 & 32 & 101 & 36 \\
\hline & C-D & MPI-ESM1-2-LR_r6i1p1f1 & 36 & 29 & 20 & 85 & 31 \\
\hline & & MPI-ESM1-2-LR_r7i1p1f1 & 35 & 33 & 23 & 91 & 33 \\
\hline & $\mathrm{C}-\mathrm{W}$ & IPSL-CM6A-LR_r1i1p1f1 & 26 & 7 & 33 & 66 & 21 \\
\hline & & IPSL-CM6A-LR_r3i1p1f1 & 34 & 13 & 13 & 60 & 17 \\
\hline
\end{tabular}

LR; Lower region, MR; middle region, UR; Upper region

For temperature, some GCMs underestimated, and others overestimated the observed probability. Overall, the skill score of 33 out of the 36 models exceeds 0.6 in each subregion. INM-CM5-0_r1ilp1f1 (0.79), ACCESSCM2_r2ilp1f1 (0.77), INM-CM5-0_r1i1p1f1 (0.79), from the lower, middle and upper subregion represents a good correlation between model and observed dataset. While from the middle subregion of the study area, CanESM5_r1i1p2f1 (0.47) and from the lower subregion CanESM5_r10i1p2f1 (0.49) performs the worst, while no model scores less than 0.5 in the upper subregion. In general, GCM runs PDFs for air temperature showed a good agreement against NCEP/DOE observations. For SSP4.5 during the mid-century period, the skill score obtained for 411 the individual subregions and corners shows that CanESM5_r10i1p2f1 has (0.57) for W-D corner, INM-CM4412 8_r1ilp1f1 (0.53) for W-W, and CanESM5_r10i1p2f1 (0.49) for the W-D corner in the lower, middle and upper 413 subregions respectively. While INM-CM5-0_r1i1p1f1 (0.79) for W-W corner, IPSL-CM6A-LR_r6i1p1f1 (0.74) C414 W corner and INM-CM5-0_r1i1p1f1 (0.79) W-W corner under the respected subregions. This result showed that INM415 CM5-0_r1i1p1f1 and IPSL-CM6A-LR_r6i1p1f1 models perform well in replicating the observed temperature. 416 However, the remaining models had limited skills. For SSP4.5 in the end-century period INM-CM5-0_r1i1p1f1 (0.79) 417 for W-W corner, IPSL-CM6A-LR_r2i1p1f1 (0.72) for C-W corner and INM-CM5-0_r1i1p1f1 (0.9) for W-W are the 418 best performing models out of $13 \mathrm{GCMs}$ in lower, middle and upper subregions respectively. While 419 CanESM5_r7i1p2f1 (0.58) CanESM5_r4i1p2f1 (0.58), INM-CM4-8_r1i1p1f1(0.56) and MPI-ESM1-2-LR_r9i1p1f1 420 (0.52) had a less skill for temperature for W-D, W-W and C-D corners respectively for the respected corners. This 421 implied those models have less capability in simulating the climate of the study area. The overall performance of the 422 models over observed PDF is generally good. Taylor diagram (TD) simulates the degree of agreement between GCM 423 models and the reanalysis dataset. Figure 4-6 show the TD for temperature over the individual subregion in UAB. The 424 golden dot and aqua dot (radial axis) inside the graph indicate RMSE and correlation coefficient between the modelled 425 and reference data set, while the blue line shows each dataset standard deviation. 


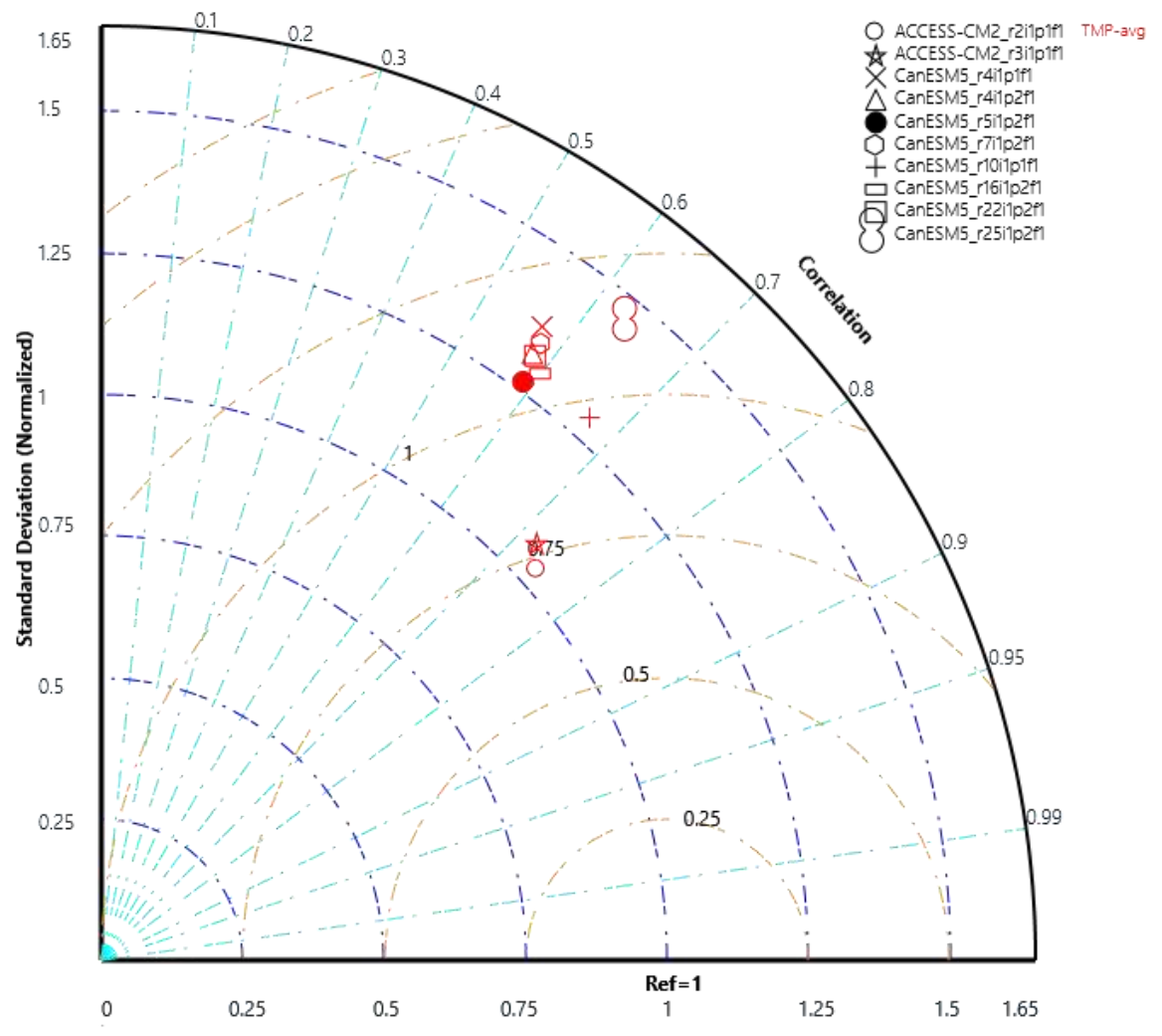

427 


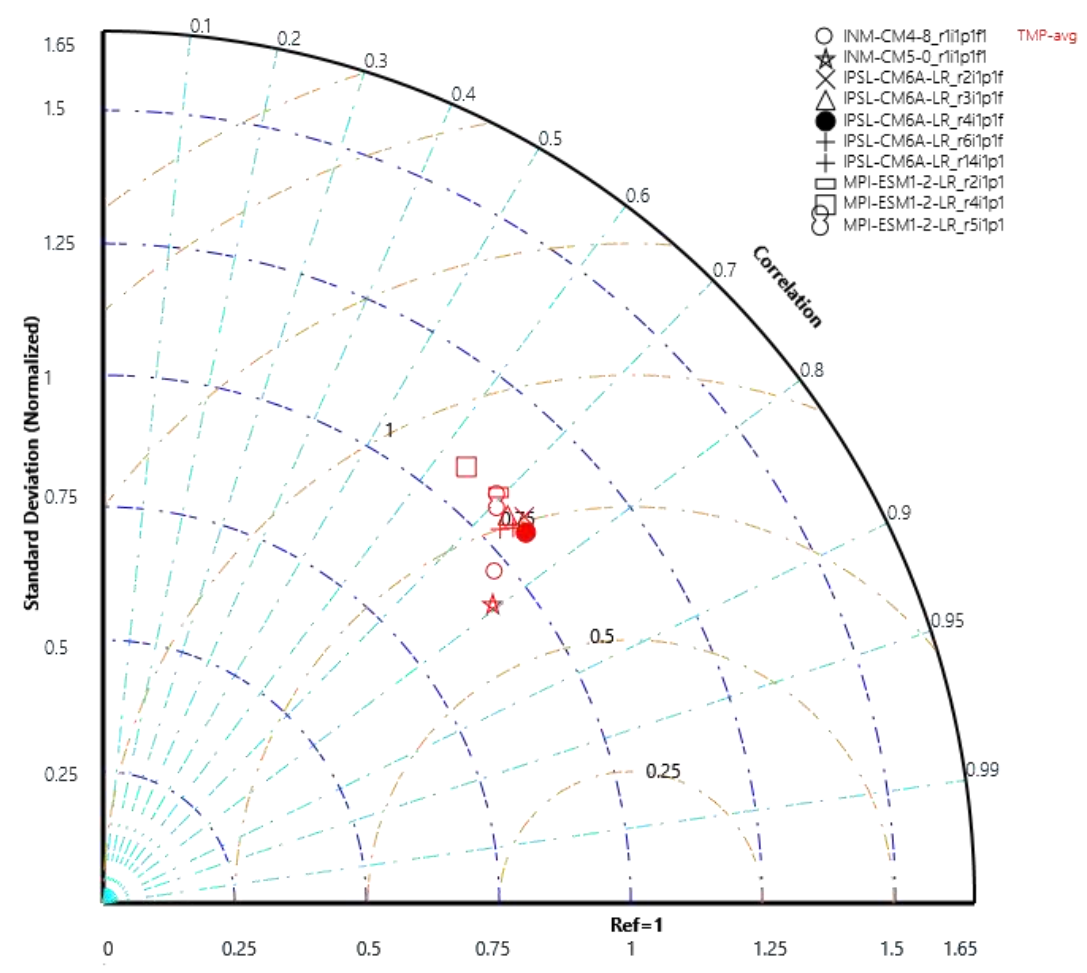

428

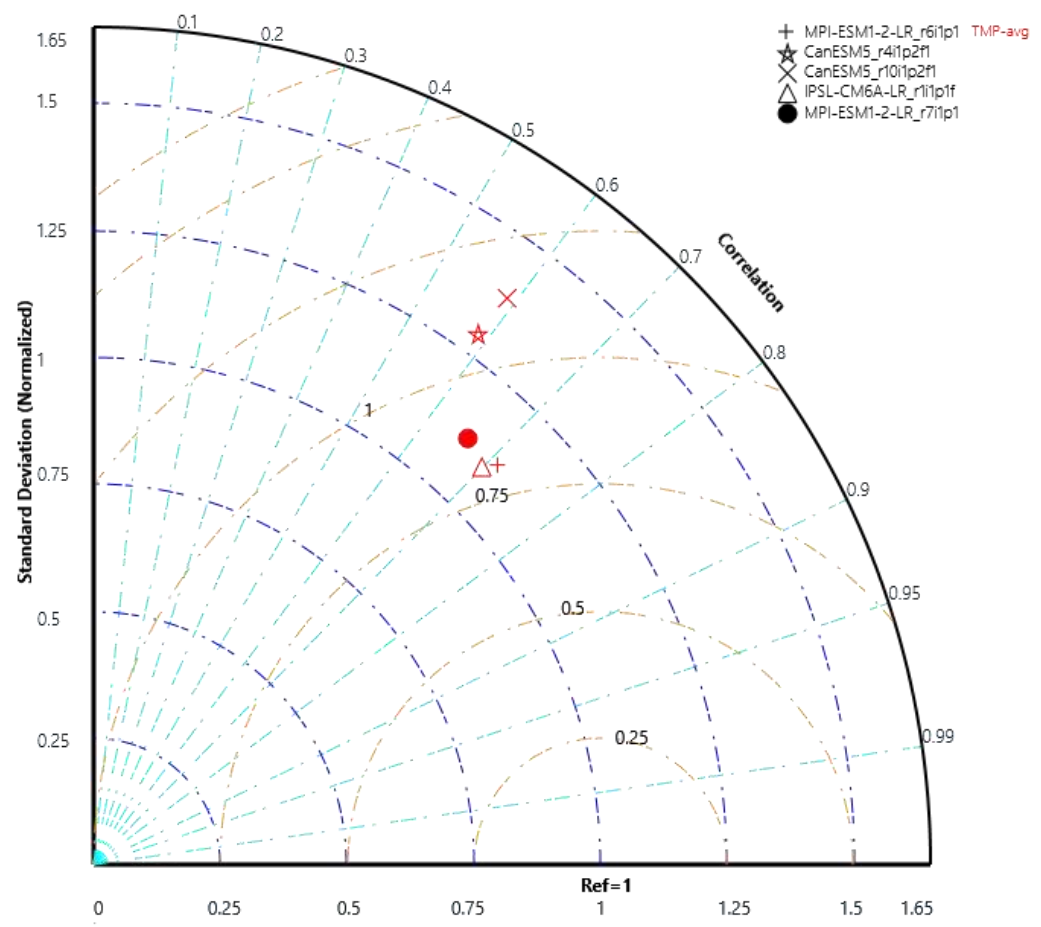




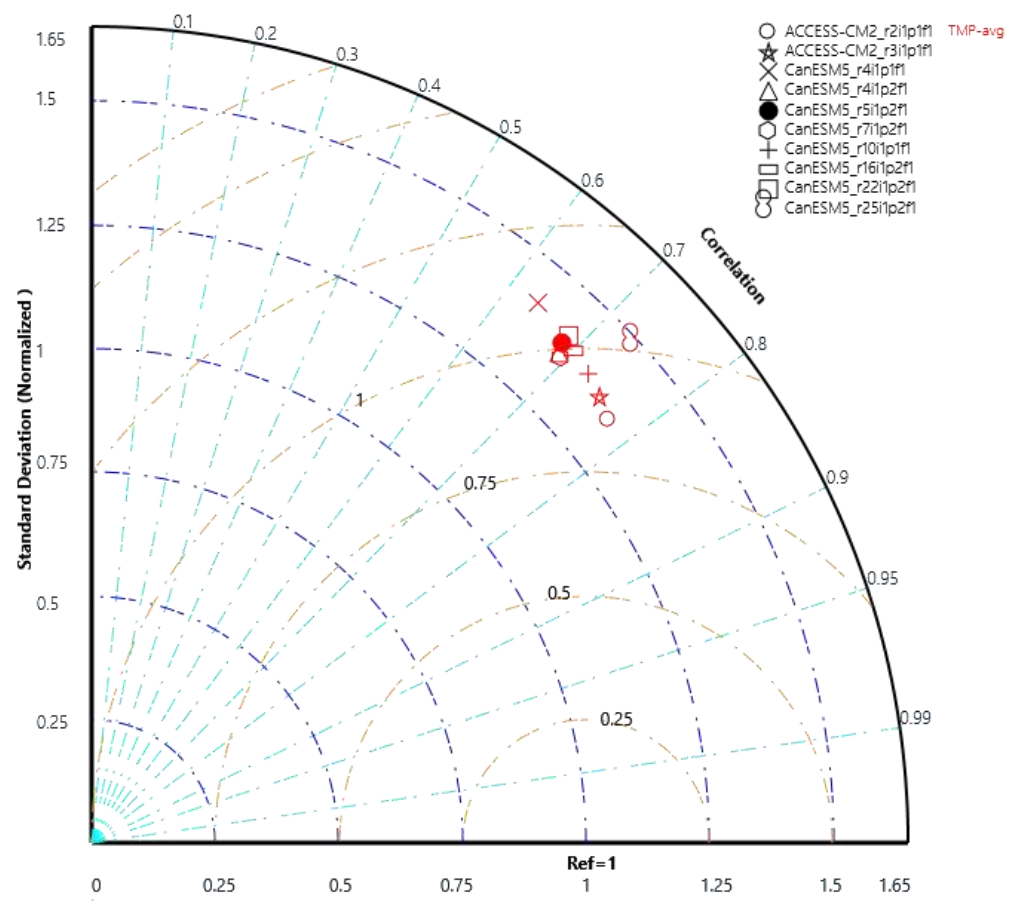

431 


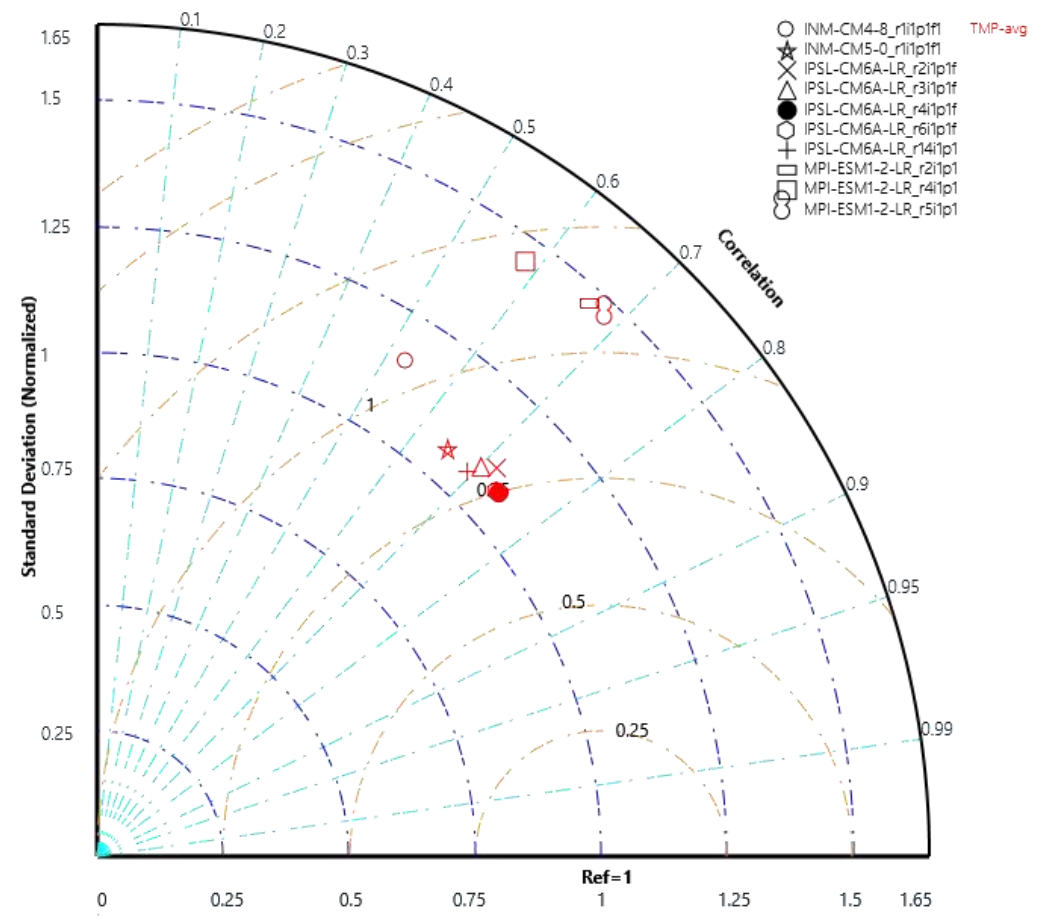

432

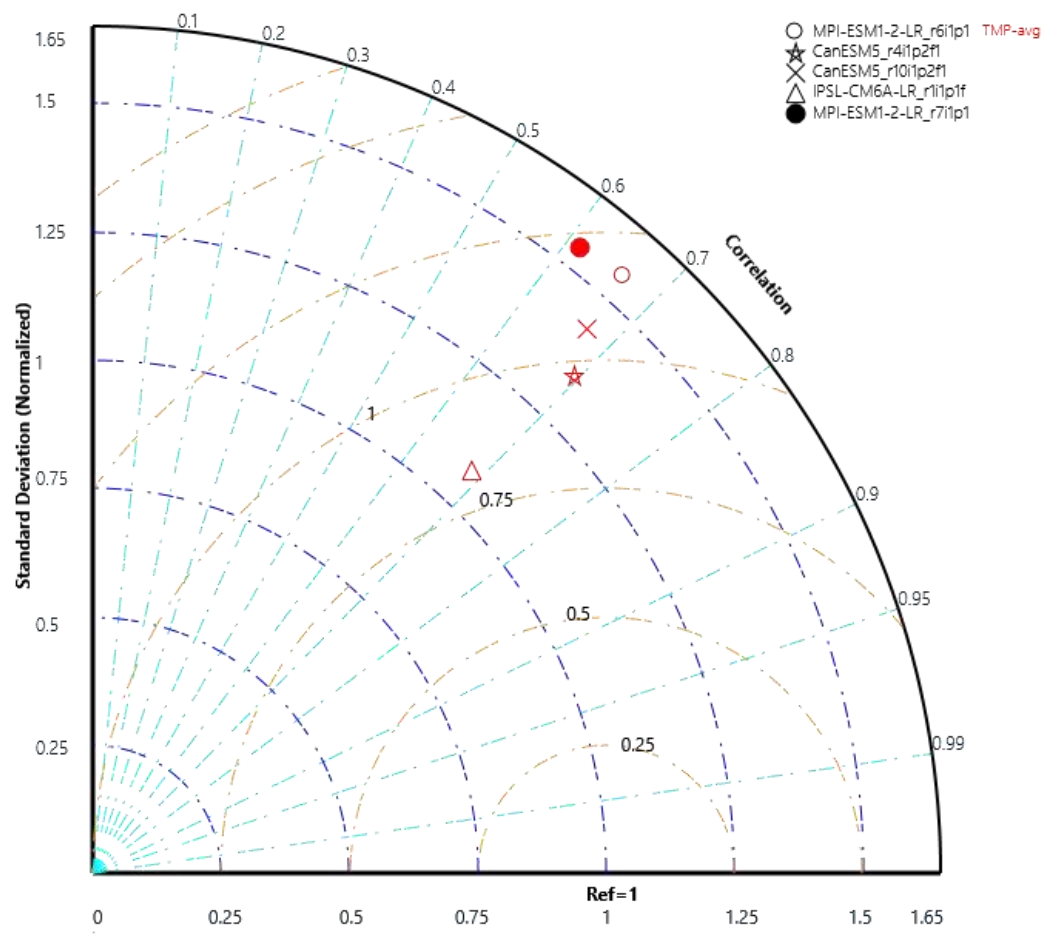

Fig. 5 The Taylor diagram for evaluating the model and reanalysis monthly temperature over MR of UAB 


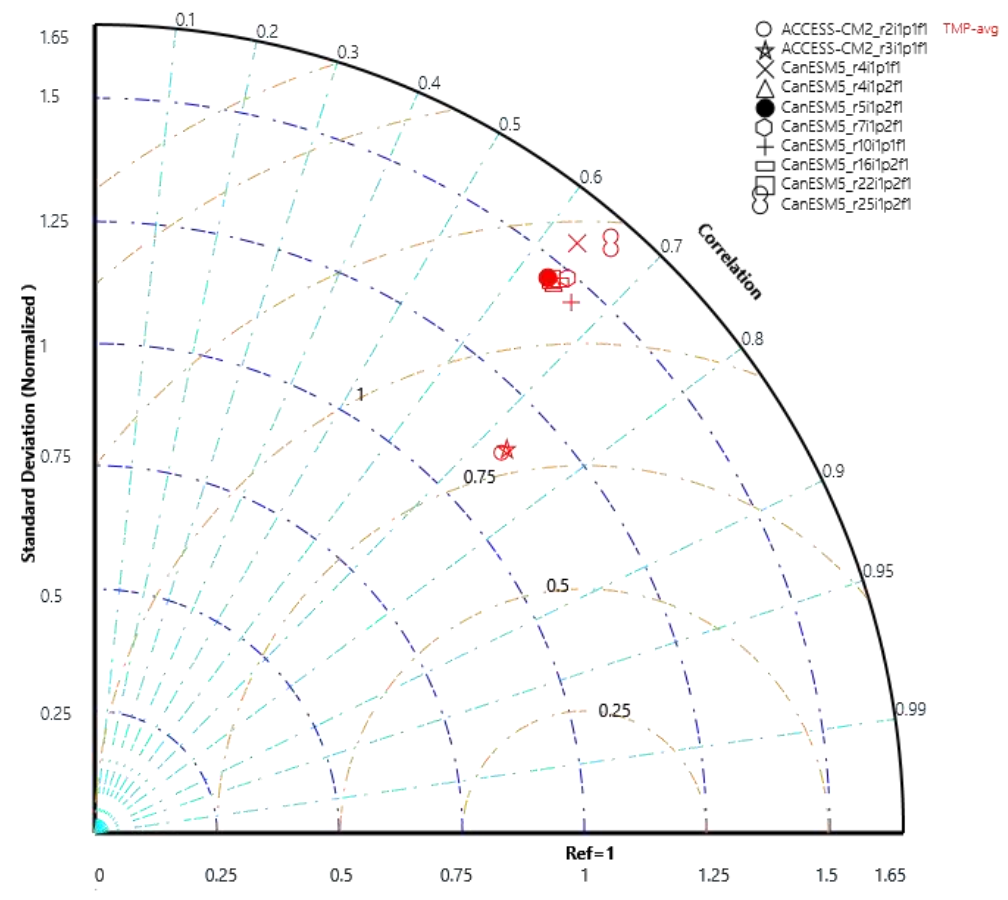

435 


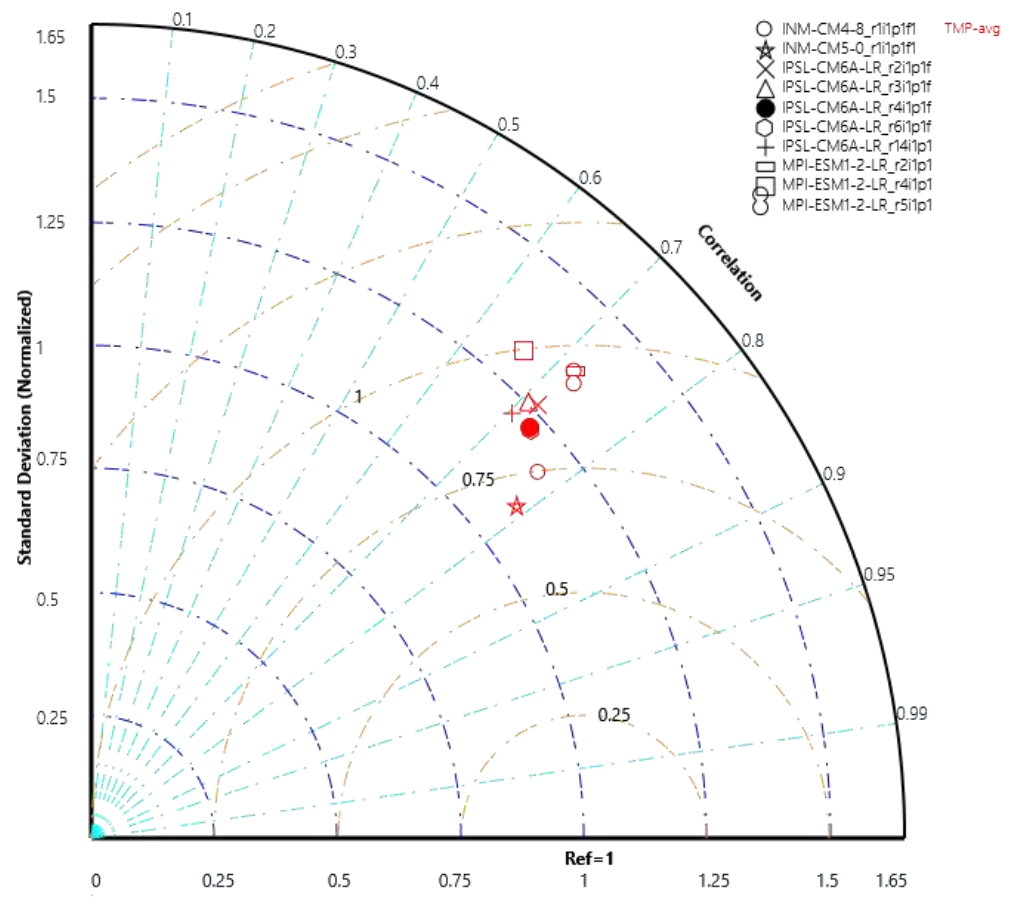

436

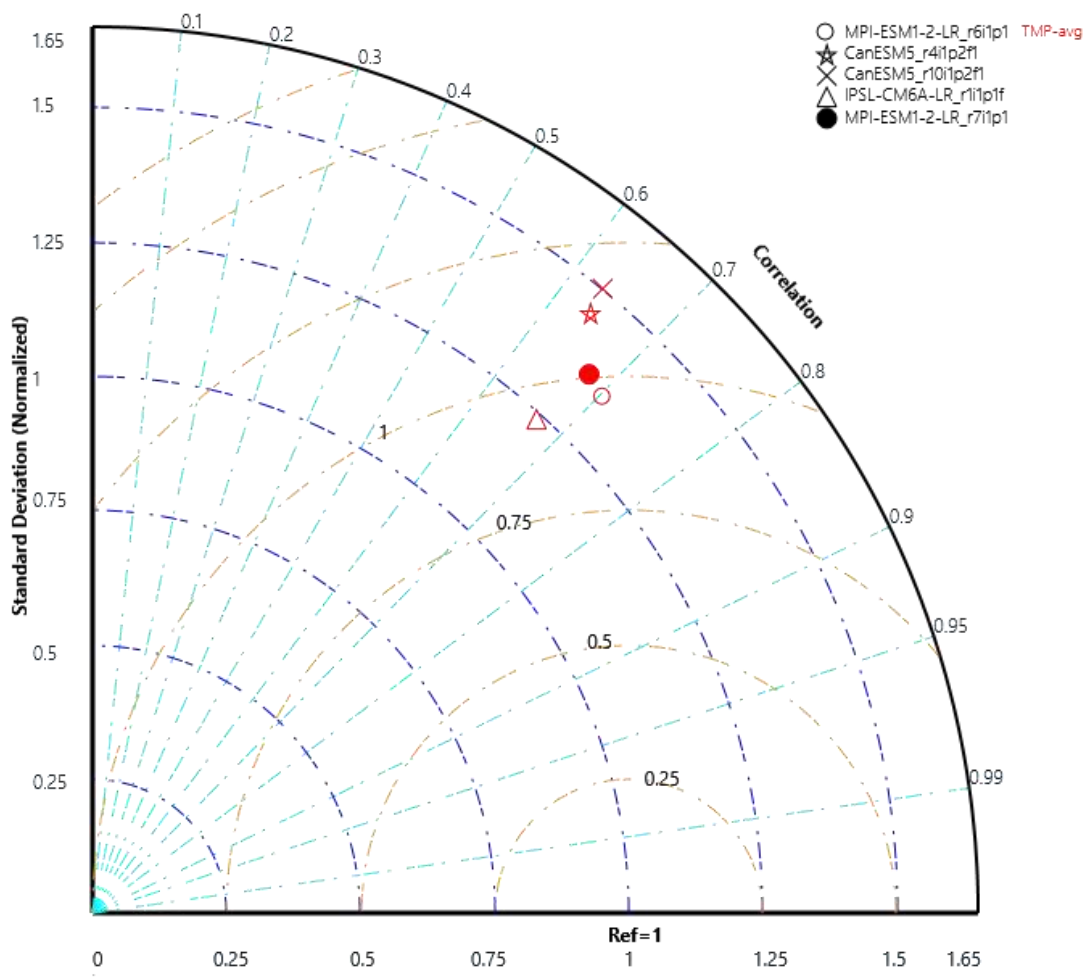

Fig. 6 The Taylor diagram for evaluating the model and reanalysis monthly temperature over UR of UAB 
In general, the skill score value of the specific model in temperature among the lower, middle, and upper subregions are not too varying, and the overall performance of the models over the specific subregions is generally good. The GCM air temperature reasonably simulated the observed PDFs. Finally, those climate models that are

442 skillful over the UAB are identified, and those models will be applicable for future impact assessments.

For precipitation, the skill score result obtained for the individual subregions showed INM-CM4-8_r1i1p1f1 (0.61) in the lower subregion INM-CM4-8_r1ilp1f1 (0.68) in the middle subregion are the best performers in capturing the observed PDFs. INM-CM4-8_r1i1p1f1 is closer to observation than any individual model. And a few GCM models perform well and fit the observed precipitation PDF. In contrast, the upper subregion is the worst performing area, with INM-CM4-8_r1ilp1f1 having the highest value of 0.18. Many models are also less than 0.5 in the three subregions. For many models, the comparison is not good. The monthly PDFs of GCMs are underestimated compared to observations in the three subregions. Temperature simulated the observed data better than precipitation variables, the correlation between the GCMs and observed precipitation data is low. MPI-ESM1-2-LR_r4i1p1f1, 451 CanESM5_r25i1p2f1, and CanESM5_r10i1p2f1 are the worse-performing models with the scores of 0.05, 0.07, and 4520.08 , respectively. Therefore, models with low combined skill scores are omitted, indicating high bias. Overall, the 453 PDFs of GCMs simulation do not fit the observed dataset except for the INM-CM4-8_r1i1p1f1 model. In different 454 periods and under different SSPs, different models are selected. Many models could capture the major properties of 455 UAB climatology and can be applied for future climate projections. The final selected model outputs were used for 456 downscaling and bias correction of the climate variables intended for future impact assessment studies.

Table 7 Final selected GCM runs with projected changes in mean air temperature, precipitation and ETCCDI indices between 1981-2010 and 2031-2060, 2061-2090 averaged over the study area

\begin{tabular}{|lllllllll|}
\hline \multirow{2}{*}{ SSP /Year } & Projection & GCM Run & $\begin{array}{l}\Delta \text { P } \\
(\%)\end{array}$ & $\begin{array}{l}\Delta \text { T } \\
\left({ }^{\circ} \mathbf{C}\right)\end{array}$ & $\begin{array}{l}\Delta \text { CDD } \\
(\%)\end{array}$ & $\begin{array}{l}\Delta \text { R95PTOT } \\
(\%)\end{array}$ & $\begin{array}{l}\Delta \text { WSDI } \\
(\%)\end{array}$ & $\begin{array}{l}\Delta \text { CSDI } \\
(\%)\end{array}$ \\
\hline \multirow{5}{*}{ SSP4.5/2031-2060 } & W-D & CanESM5_r25i1p2f1 & -3.6 & 7.8 & 26.3 & 24.0 & 11847.0 & -100.0 \\
& W-W & INM-CM4-8_r1i1p1f1 & 3.0 & 5.4 & -18.2 & -29.5 & 10481.6 & -100.0 \\
& C-D & MPI-ESM1-2-LR_r6i1p1f1 & -2.7 & 2.6 & 46.4 & -77.7 & 8142.2 & -87.8 \\
& C-W & IPSL-CM6A-LR_r14i1p1f1 & 1.7 & 2.9 & 42.6 & 21.3 & 5917.6 & 9.6 \\
SSP4.5/2061-2090 & W-D & CanESM5_r7i1p2f1 & -2.3 & 8.6 & 6.2 & 55.9 & 11977.3 & -100.0 \\
& W-W & INM-CM4-8_r1i1p1f1 & 3.7 & 5.8 & -26.8 & -18.7 & 11048.5 \\
& C-D & MPI-ESM1-2-LR_r5i1p1f1 & -2.3 & 3.1 & 58.5 & -77.3 & 9200.0 & -100.0 \\
& C-W & IPSL-CM6A-LR_r4i1p1f1 & 3.4 & 3.8 & 41.6 & 49.6 & 8416.5 & -89.2 \\
SSP8.5/2031-2060.3 & W-D & CanESM5_r22i1p2f1 & -2.8 & 8.2 & 35.8 & 34.5 & 11897.2 & -100.0 \\
& W-W & INM-CM4-8_r1i1p1f1 & 3.5 & 5.8 & -23.1 & -24.6 & 10957.2 & -100.0 \\
& C-D & MPI-ESM1-2-LR_r5i1p1f1 & -2.5 & 2.9 & 77.8 & -81.7 & 8664.2 & -91.4 \\
& C-W & IPSL-CM6A-LR_r6i1p1f1 & 1.7 & 3.5 & 51.3 & 29.4 & 7470.4 & -52.0 \\
& W-D & ACCESS-CM2_r2i1p1f1 & -2.4 & 8.1 & 23.9 & -1.1 & 12111.0 & -100.0 \\
& W-W & CanESM5_r1i1p2f1 & 2.9 & 10.0 & 29.8 & 17.9 & 12109.7 & -100.0 \\
& C-D & MPI-ESM1-2-LR_r6i1p1f1 & -1.7 & 4.3 & 57.0 & -78.5 & 11045.9 & -100.0 \\
& C-W & IPSL-CM6A-LR_r3i1p1f1 & 6.0 & 5.7 & 11.9 & 88.7 & 11058.7 & -98.0 \\
\hline
\end{tabular}


Table 8 Performance indicator value of the three statistical downscaling methods in terms of their skill in limiting the biases relative to observation datasets.

\begin{tabular}{|c|c|c|c|c|c|c|c|c|c|c|c|}
\hline & & & & Precipita & & & & Tempera & ure & & \\
\hline & & & & & ormance ind & tors & & Per & ormance ind & cators & \\
\hline Projection & SSP/Year & Models & Method & Pearson & Spearman & $\begin{array}{l}\text { Index of } \\
\text { agreement }\end{array}$ & $\begin{array}{l}\text { Best } \\
\text { method }\end{array}$ & Pearson & Spearman & $\begin{array}{l}\text { Index of } \\
\text { agreement }\end{array}$ & $\begin{array}{l}\text { Best } \\
\text { method }\end{array}$ \\
\hline & & & Delta & 0.367 & 0.518 & 0.599 & & 0.57 & 0.558 & 0.708 & \\
\hline W-D & SSP4.5/ 2031-2060 & CanESM5_r25i1p2f1 & QM & 0.403 & 0.525 & 0.526 & EQM & 0.57 & 0.558 & 0.752 & EQM \\
\hline & & & EQM & 0.524 & 0.554 & 0.616 & & 0.57 & 0.561 & 0.751 & \\
\hline & & & Delta & 0.675 & 0.638 & 0.81 & & 0.547 & 0.582 & 0.729 & \\
\hline C-D & & MPI-ESM1-2-LR_r6i1p1f1 & QM & 0.675 & 0.637 & 0.65 & Delta & 0.547 & 0.582 & 0.729 & QM \\
\hline & & & EQM & 0.668 & 0.632 & 0.636 & & 0.531 & 0.582 & 0.718 & \\
\hline & & & Delta & 0.679 & 0.639 & 0.821 & & 0.713 & 0.73 & 0.835 & \\
\hline $\mathrm{C}-\mathrm{W}$ & & IPSL-CM6A-LR_r14i1p1f1 & QM & 0.645 & 0.627 & 0.717 & Delta & 0.713 & 0.73 & 0.84 & QM \\
\hline & & & EQM & 0.584 & 0.62 & 0.664 & & 0.707 & 0.727 & 0.837 & \\
\hline & & & Delta & 0.601 & 0.622 & 0.741 & & 0.725 & 0.77 & 0.845 & \\
\hline W-W & & INM-CM4-8_r1ilp1f1 & QM & 0.594 & 0.616 & 0.511 & Delta & 0.725 & 0.77 & 0.844 & QM \\
\hline & & & EQM & 0.575 & 0.61 & 0.488 & & 0.731 & 0.769 & 0.848 & \\
\hline & & & Delta & 0.326 & 0.493 & 0.564 & & 0.555 & 0.553 & 0.71 & \\
\hline W-D & SSP4.5/ 2061-2090 & CanESM5_r7i1p2f1 & QM & 0.36 & 0.498 & 0.483 & EQM & 0.555 & 0.553 & 0.745 & QM \\
\hline & & & EQM & 0.487 & 0.522 & 0.584 & & 0.552 & 0.558 & 0.742 & \\
\hline & & & Delta & 0.665 & 0.644 & 0.804 & & 0.568 & 0.631 & 0.739 & \\
\hline C-D & & MPI-ESM1-2-LR_r5ilp1f1 & QM & 0.665 & 0.642 & 0.65 & Delta & 0.568 & 0.631 & 0.739 & Delta \\
\hline & & & EQM & 0.661 & 0.638 & 0.638 & & 0.572 & 0.637 & 0.741 & \\
\hline & & & Delta & 0.679 & 0.647 & 0.821 & & 0.716 & 0.738 & 0.834 & \\
\hline $\mathrm{C}-\mathrm{W}$ & & IPSL-CM6A-LR_r4i1p1f1 & QM & 0.644 & 0.633 & 0.715 & Delta & 0.716 & 0.738 & 0.841 & QM \\
\hline & & & EQM & 0.579 & 0.615 & 0.656 & & 0.709 & 0.737 & 0.837 & \\
\hline & & & Delta & 0.601 & 0.622 & 0.741 & & 0.725 & 0.77 & 0.845 & \\
\hline W-W & & INM-CM4-8_r1ilp1f1 & QM & 0.594 & 0.616 & 0.511 & Delta & 0.725 & 0.77 & 0.844 & QM \\
\hline & & & EQM & 0.575 & 0.61 & 0.488 & & 0.731 & 0.769 & 0.848 & \\
\hline & & & Delta & 0.665 & 0.644 & 0.804 & & 0.57 & 0.558 & 0.708 & \\
\hline C-D & SSP8.5 /2030-2060 & MPI-ESM1-2-LR_r5ilp1f1 & QM & 0.665 & 0.642 & 0.65 & EQM & 0.57 & 0.558 & 0.752 & QM \\
\hline & & & EQM & 0.661 & 0.638 & 0.638 & & 0.57 & 0.561 & 0.751 & \\
\hline
\end{tabular}




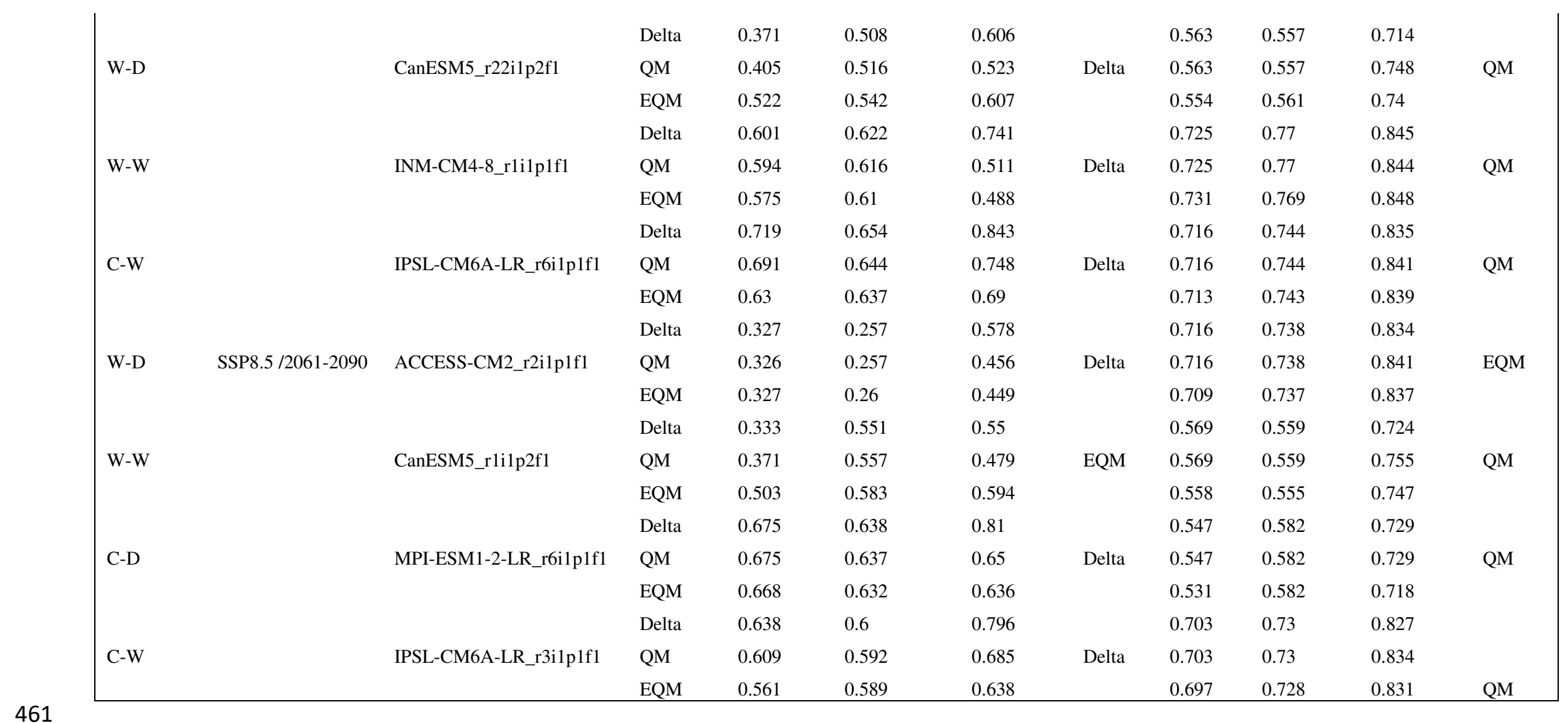




\subsection{Statistical downscaling and bias correction (SDBC)}

A total of 16 climate projections of daily precipitation and average air temperature are downscaled over UAB. Three performance indicators, namely: Pearson, Spearman and Index of Agreement, were used to identify the performances of CMIP6 relative to the observed dataset. Table 8 compared the performance indicator value of the three statistical downscaling methods in terms of their capability to downscale models with effectively removing the climate model biases relative to observation datasets. Precipitation increased in the upper section while decreased in the lower section of UAB. The most significant increases of average monthly precipitation were projected for Sendafa station located upstream, among the highest elevation of the UAB, while the least increases were projected in the downstream section of the basins called Meki station. Over the 20 stations, the selected GCM runs compared to base years precipitation, future monthly percentage changes ranging are expected to increase from $0.42 \%$ to $2.82 \%$ in mid-century and $0.15 \%$ to $3.79 \%$ in end century considering the SSP4.5. For the SSP8.5 forcing scenario, monthly average precipitation increases in the range of $1.45 \%$ to $5.51 \%$ in mid-century and $2.57 \%$ to $9.78 \%$ in end-century. The downscaled precipitation model outputs revealed that, under the SSP8.5 forcing scenario, the increment is more significant for the upstream stations than the downstream stations of the basin during 2061-2090. In contrast, during the successive periods of 2031-2060 and 2061-2090, the most robust decrease in precipitation is found in the upper section of the basin called Addis Ababa Obs. station, considering the SSP4.5 forcing scenario. Therefore, the final selected four GCM models with different ensemble members code " $r$ " (realizations) " $i$ " (initialization methods), " $p$ " (physics details) " $f$ " (forcing) are namely, CanESM5, MPI-ESM1-2-LR, IPSL-CM6A-LR, INM-CM4-8, and ACCESS-CM2. In the two forcing scenarios and study periods, the maximum monthly average precipitation in all stations is expected to increase for CanESM5 and IPSL-CM6A-LR. While in the mid-term period, three of the four GCMs were found to be decreased, namely MPI-ESM1-2-LR_r6i1p1f1 (-0.81\%), INM-CM4-8_r1i1p1f1 (-0.45\%) and MPI-ESM1-2-LR_r5i1p1f1 (-0.90\%), INM-CM4-8_r1i1p1f1 (-0.09\%) for SSP4.5 and SSP8.5 respectively in Addis Ababa Obs. stations. In contrast, average monthly precipitation was found to increase for CanESM5_r25i1p2f1 $(+2.82 \%)$ in Koka Dam station , IPSL-CM6A-LR_r14i1p1f1 $(+0.42 \%)$ in Meki station and CanESM5_r22i1p2f1 (5.51\%) Meki station IPSL-CM6A-LR_r6ilp1f1 in Sendafa station (1.45\%) under SSP4.5 and SSP8.5 forcing scenarios respectively. During 2061-2090 period, three of the four ensemble models in the two forcing scenarios have predicted an increased in precipitation for CanESM5_r7i1p2f1 (+3.79\%) Koka Dam station, IPSL-CM6A-LR_r4i1p1f1 (+2.81\%) Sendafa station, INM-CM4-8_r1i1p1f1 (0.15\%) Addis Ababa Obs station, considering SSP4.5 and CanESM5_r1i1p2f1 (+2.57\%) in Koka Dam station, MPI-ESM1-2LR_r6ilp1f1 (+9.78\%) in Sendafa station, and IPSL-CM6A-LR_r3ilp1f1 (+4.18\%) Sendafa station considering SSP8.5. However, one ensemble model out of four selected model runs decreased the monthly maximum precipitation in both scenarios, MPI-ESM1-2-LR_r5ilp1f1 (-0.40\%) Addis Ababa Obs., ACCESSCM2_r2i1p1f1 (-0.88\%) busa station, considering SSP4.5 and SSP8.5 forcing scenario, respectively. Generally, the ensemble mean of the selected GCMs revealed variability for precipitation changes in the UAB.

The monthly average temperature is expected to increase in the 2031-2060 period, which is projected to be from $0.68^{\circ} \mathrm{C}$ to $1.55^{\circ} \mathrm{C}$ and $0.19^{\circ} \mathrm{C}$ to $1.98^{\circ} \mathrm{C}$, under SSP 4.5 and SSP 8.5 forcing scenarios, while that in $2061-2090$ was from $0.09^{\circ} \mathrm{C}$ to $1.92^{\circ} \mathrm{C}$ and $2.37^{\circ} \mathrm{C}$ to $7.00^{\circ} \mathrm{C}$ under the respective scenarios. The SSP8.5 is projected to increase more than the SSP4.5 scenarios for the two future periods. In addition, there is a hightemperature variation between the base and future periods among the Upper Awash stations. During the base 
period, the highest monthly average temperature was recorded in the Koka dam station $\left(27.38^{\circ} \mathrm{C}\right)$ in the lower region of the basin. Similarly, the most significant increases are projected for Melkasa station $\left(31.8^{\circ} \mathrm{C}\right)$ in the lower region of the basin. The historical temperature records align with what we found for the future projection. The historical and projected average temperature values are high at the lowest elevation of the river basin. A higher increase in temperature is expected in the lower section of the basin compared to the upper region of the basin at the end-of-century period. In contrast, the lowest increases are projected for the most upstream parts of the basins, including Addis Ababa, the capital of Ethiopia. Our study reveals that elevation-dependent warming may become more pronounced in the future in this river basin. PDF and CDF of downscaled precipitation and average temperature respectively for observed and GCM runs per station is shown in Figure 7 and 8.

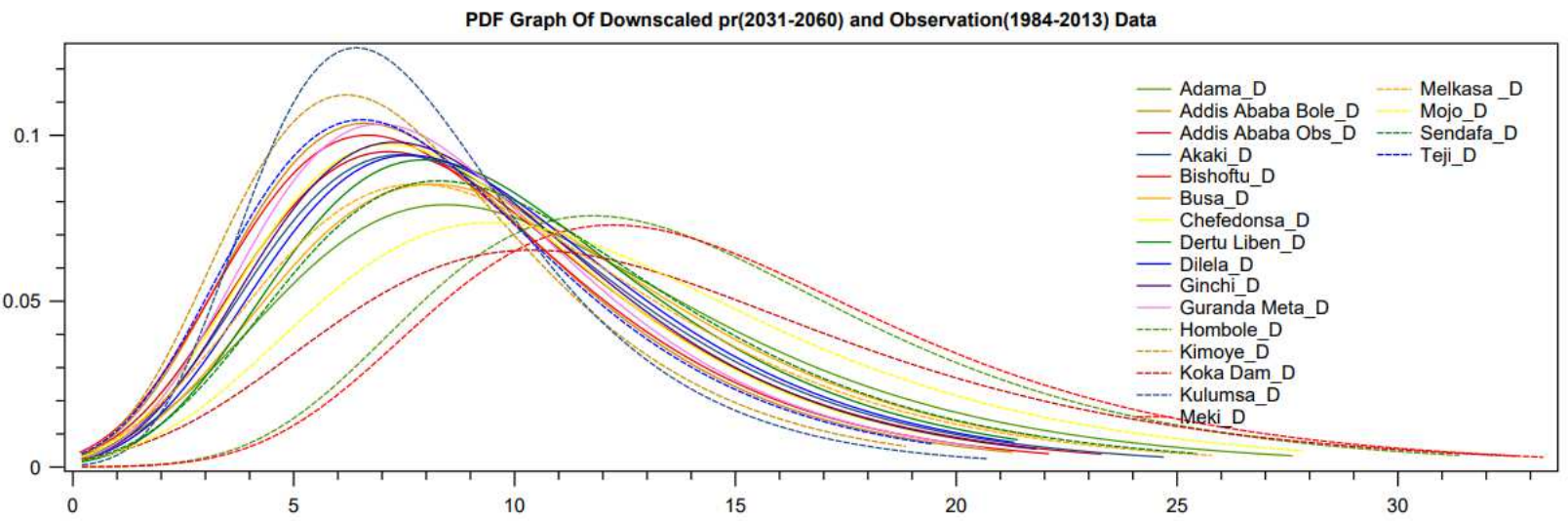

(b)
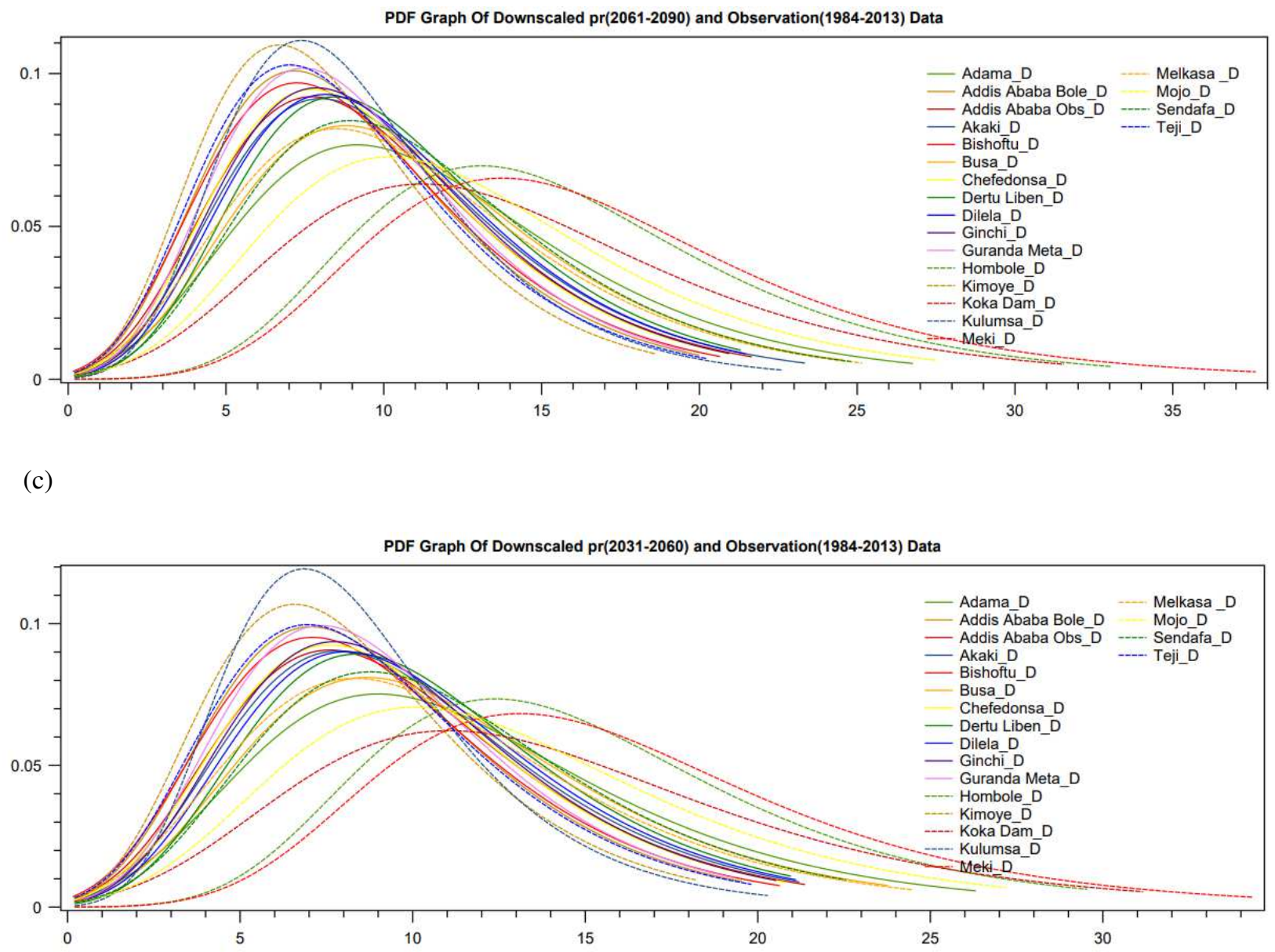
519

Fig. 7 PDF of monthly downscaled precipitation for observed and GCM runs per station (a) CanESM5_r25i1p2f1 CanESM5_r25i1p2f1 (b) CanESM5_r7i1p2f1 (c) CanESM5_r22i1p2f1 respectively

521

(c)

(a)

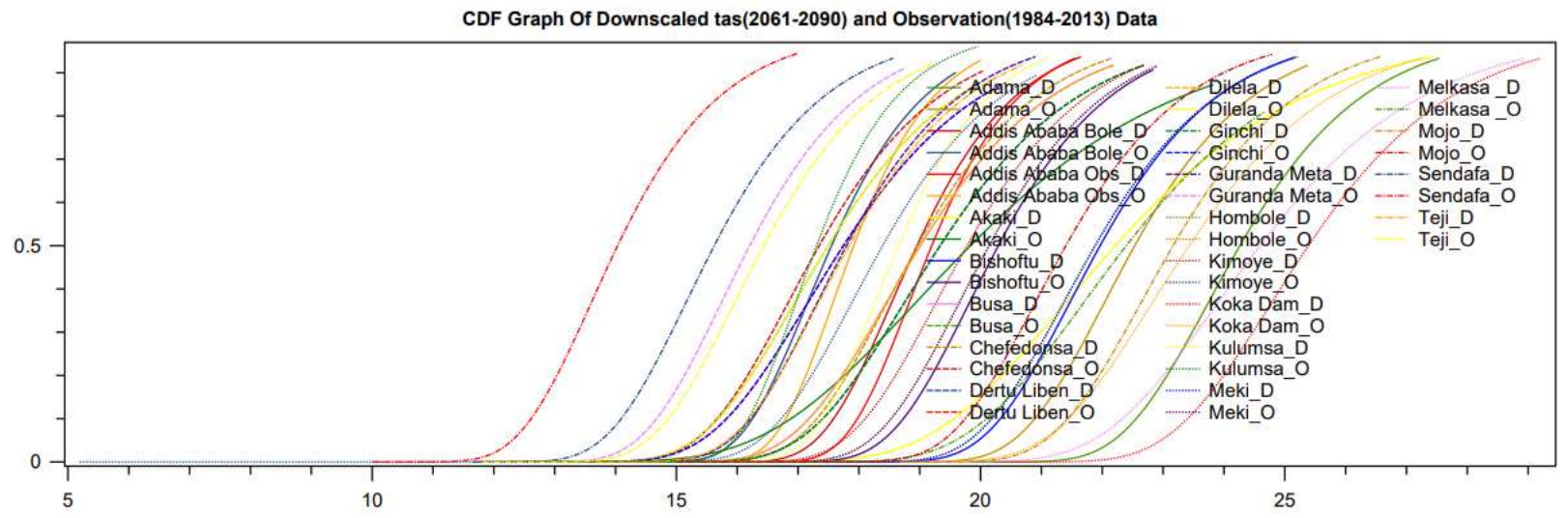

(b)
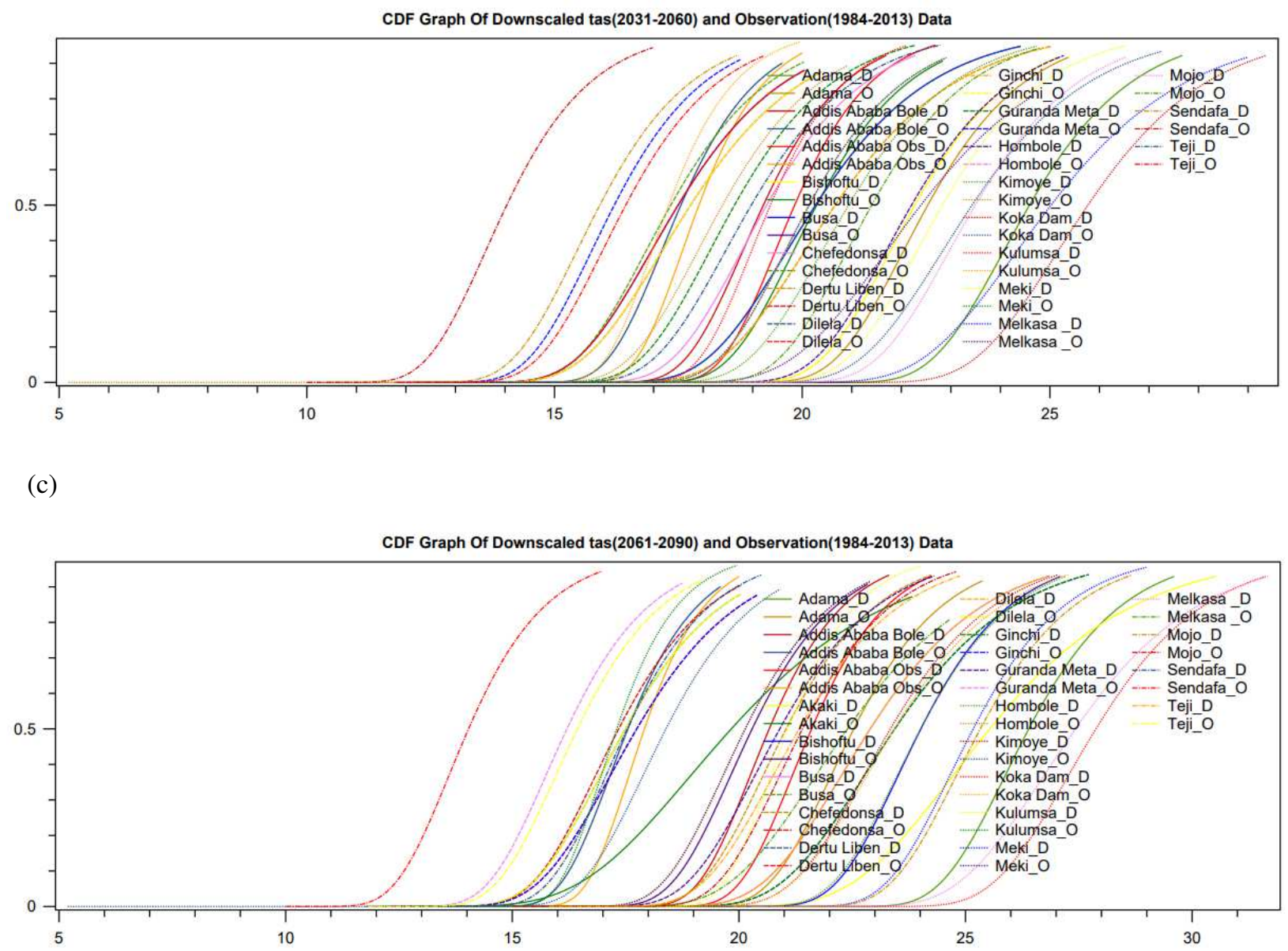

Fig. 8 CDF of monthly downscaled average temapature for observed and GCM runs per station (a) MPI-ESM1-2-LR_r5i1p1f1 (b) IPSL-CM6A-LR_r6i1p1f1 (c) IPSL-CM6A-LR_r3i1p1f1 respectively

\section{Conclusion}

The model selection and downscaling approach were applied for future climate projections of two socioeconomic pathways (SSPs), SSP4.5, SSP8.5, and two study periods (2031-2060 and 2061-2090). The annual projected mean of temperature and precipitation, climate extreme indices, and model skill in simulating the past 
climate with respect to the NCEP-DOE reference data set were applied to identify a representative set of climate model runs. Average temperature and precipitation variables from GCMs were downscaled and bias-corrected for the two periods. The GCM runs identified using the method described in the current study are planned to be used as input to SWAT models for future climate impact assessment over UAB in later stages of the research.

The downscaled temperature and precipitation distribution show distinct patterns across the study region. Precipitation spatial distribution for all periods/scenarios considered a decrease in the downstream section of the basin, but an increase in the mountainous parts of the basin, highly an increasing pattern also observed for temperature in all parts of the region. Both increments in temperature and precipitation during the two study periods are higher under the SSP8.5 scenario than in the SSP4.5 scenario. Proper management is necessary for an important basin such as the $\mathrm{UAB}$, which is primarily used for domestic, agricultural and industrial water supply for a very populace city such as Addis Ababa, the capital of Ethiopia, and other surrounding urban

cities.

This study presents a representative GCM run selection method for impact studies intended to combine the strength of two approaches of envelope-based and past-performance-based, which contains multiple criteria to select the appropriate models for climate impact studies over UAB, Ethiopia. The adopted technique allows more accuracy and reduces uncertainties in the futuristic investigation. The advanced envelope-based technique addresses the drawback of the previous selection approaches and provides a modified method. However, certain limitations are discussed therein.

During the initial and refined selection, the analysis considered the step-wise screening of the several ensemble models based on projected change of annual mean and extremes, respectively. Both the projected mean change and mean change in the extreme are spatially averaged over the entire area. The application scale in both steps may dilute the spatial variation in projected changes. Additionally, the selection approach of changes in means may reduce GCMs, resulting in fewer available models that will undergo climatic extremes evaluation. Similarly, the skill score-based simulation for evaluating past performance may have missed good models that can simulate the past climate with good ability. This is because the approach is presented in the final step, with fewer climate models available than the first and second steps. Therefore, the selected models could not necessarily have the best skill in simulating past climates. The other limitation has to do with the final skill scores calculation. The final skill score was calculated based on the minimum combined bias score of temperature and precipitation; such a way may have omitted those models with good performance in other subdomains.

The impact of climate change is evident around the world, including Ethiopia. Numerous studies are conducted on climate change in UAB but lack proper utilization of GCMs. Uncertainties exist in applying these models as the number of models increases. Therefore, this study is the first of its kind in Ethiopia, and the established result is vital for regional climate change impact analysis. It will be helpful to the Awash Basin Authority and potential researchers for proper usage of these models, including forcing hydrological models.

Acknowledgments The authors would like to acknowledge the National Meteorology Agency (NMA) of Ethiopia for providing meteorological data. The authors also acknowledge the Earth System Grid Federation (ESGF) for archiving and accessing the CMIP6 dataset. 
578 Data availability The full set of raw data and the analyzed output that supports the findings of this study are 579 available in the supplementary file.

580 Code availability The codes that support the findings of this study are available from the corresponding 581 author (wzyhhu@gmail.com).

582 Author contribution Selamawit Haftu Gebresellase contributed to conceptualization, data curation,

583 conducted formal analysis, methodology, investigation, analyzed all datasets, results, visualization, writing the 584 original manuscript, review and editing. Zhiyong $\mathrm{Wu}$ (as the corresponding author) contributed to supervision, project administration, pursuing ideas and guidance, revised and edited the manuscript. Huating $\mathrm{Xu}$ contributed to review and to editing. Wada Idris Muhammad contributed to editing.

\section{Declarations}

588

Consent for publication The authors give their consent to the publication of all details of the manuscript, including texts, figures, and tables.

Conflict of interest The authors declare no competing interests.

591

592

593

594

595

596

597

598

599

600

601

602

603

604

605

606

607

608

609

610 


\section{References}

Aich V, Liersch S, Vetter T, Huang S, Tecklenburg J, Hoffmann P, Müller, E (2014) Comparing impacts of climate change on streamflow in four large African river basins. Hydrology Earth System Sciences 18(4):1305-1321, DOI 10.5194/hess-18-1305-2014

Annan JD, Hargreaves JCJGRL (2010) DOI 10.1029/2009GL041994, URL https://doi.org/10.1029/2009GL041994

Bader DC, Covey C, Gutowski WJ, Held IM, Miller RL, Tokmakian RT, Zhang MH (2008) URL https://dr.lib.iastate.edu/handle/20.500.12876/38323

Bekele D, Alamirew T, Kebede A, Zeleke G, Melesse AMJEM, Assessment (2019) Modeling climate change impact on the Hydrology of Keleta watershed in the Awash River basin. Ethiopia 24(1):95-107, DOI 10.1007/s10666018-9619-1

Biemans H, Speelman L, Ludwig F, Moors E, Wiltshire A, Kumar P (2013) DOI 10.1016/j.scitotenv.2013.05.092, URL https://doi.org/10.1016/ j.scitotenv.2013.05.092

Boé J, Terray L, Habets F, Martin E (2007) Statistical and dynamical downscaling of the Seine basin climate for hydro-meteorological studies. International Journal of Climatology: A Journal of the Royal Meteorological Society 27(12):1643-1655, DOI 10.1002/joc.1602

Brown C, Greene AM, Block PJ, Giannini A (2008) DOI 10.7916/D8M04C88, URL https://doi.org/10.7916/D8M04C88

Chen ST, Yu PS, Tang YHJJ (2010) DOI 10.1016/j.jhydrol.2010.01.021, URL https://doi.org/10.1016/j.jhydrol.2010.01.021

Daba MH, You S (2020) Assessment of Climate Change Impacts on River Flow Regimes in the Upstream of Awash Basin, Ethiopia: Based on IPCC Fifth Assessment Report (AR5) Climate Change Scenarios. Hydrology 7(4), DOI 10.3390/hydrology7040098

Dessu SB, Melesse AMJHP (2013) Impact and uncertainties of climate change on the hydrology of the Mara River basin, vol 27. Kenya/Tanzania, DOI 10.1002/hyp.9434, URL https://doi.org/10.1002/hyp.9434

Dixon KW, Lanzante JR, Nath MJ, Hayhoe K, Stoner A, Radhakrishnan A, Gaitán, C CFJC (2016) DOI 10.1007/s10584-016-1598-0, URL https: //doi.org/10.1007/s10584-016-1598-0

Endris HS, Omondi P, Jain S, Lennard C, Hewitson B, Chang'a L, Nikulin, C GJJO (2013) DOI 10.1175/JCLI-D-12-00708.1, URL https://doi.org/10. 1175/JCLI-D-12-00708.1

Eyring V, Bony S, Meehl GA, Senior CA, Stevens B, Stouffer RJ, Taylor KEJGMD (2016) DOI 10.5194/gmd-9-1937-2016, URL https://doi.org/10. 5194/gmd-9-1937-2016

Finger D, Heinrich G, Gobiet A, Bauder AJWRR (2012) DOI 10.1029/ 2011WR010733, URL https://doi.org/10.1029/2011WR010733

Fu G, Liu Z, Charles SP, Xu Z, Yao ZJJOGRA (2013) DOI 10.1002/jgrd.50269, URL https://doi.org/10.1002/jgrd.50269

Gebrechorkos SH, Hülsmann S, Bernhofer C (2019a) Regional climate projections for impact assessment studies in East Africa. Environmental Research Letters 14(4):44031-44031

Gebrechorkos SH, Hülsmann S, Bernhofer C (2019b) Statistically downscaled climate dataset for East Africa. Sci Data 6(1):31-31, DOI 10.1038/s41597019-0038-1

Getahun YS, Li MH, Chen PYJW (2020) DOI 10.3390/w12051308, URL https://doi.org/10.3390/w12051308

Hay LE, Wilby RL, Leavesley GH (2000) A comparison of delta change and downscaled GCM scenarios for three mountainous basins in the United States 1. Journal of the American Water Resources Association 36(2):387-397, DOI 10.1111/j.1752-1688.2000.tb04276.x

Immerzeel W, Pellicciotti F, Bierkens MJN (2013) DOI 10.1038/ngeo189610. 1038/ngeo1896, URL https://doi.org/10.1038/ngeo1896https://doi.org/10. 1038/ngeo1896

Joetzjer E, Douville H, Delire C, Ciais PJCD (2013) DOI 10.1007/s00382-0121644-1, URL https://doi.org/10.1007/s00382-012-1644-1 
Kaini S, Nepal S, Pradhananga S, Gardner T, Sharma AK (2020) Represen- tative general circulation models selection and downscaling of climate data for the transboundary Koshi river basin in China and Nepal. International Journal of Climatology 40(9):4131-4149, DOI 10.1002/joc.6447

Kanamitsu M, Ebisuzaki W, Woollen J, Yang SK, Hnilo J, Fiorino M, Potter GJ (2002) DOI 10.1175/BAMS-83-11-1631, URL https://doi.org/10.1175/ BAMS-83-11-1631

Khan A, Koch M (2018) DOI 10.3390/cli6040089, URL https://doi.org/10. 3390/cli6040089

Kharin VV, Zwiers F, Zhang X, Wehner MJC (2013) DOI 10.1007/s 10584- 0130705-8, URL https://doi.org/10.1007/s10584-013-0705-8

Kim YH, Min SK, Zhang X, Sillmann J, Sandstad M (2020) DOI 10.1016/j. wace.2020.100269, URL https://doi.org/10.1016/j.wace.2020.100269

Knutti R, Sedláček JJN (2013) DOI 10.1038/nclimate1716, URL https://doi. org/10.1038/nclimate 1716

Legates DRJ (2002)

Lutz AF, Immerzeel WW, Gobiet A, Pellicciotti F, Bierkens M (2013) Comparison of climate change signals in CMIP3 and CMIP5 multi-model ensembles and implications for Central Asian glaciers. Journal of Hydrology Earth System Sciences 17(9):3661-3677, DOI 10.5194/hess-17-3661-2013

Lutz AF, Maat HT, Biemans H, Shrestha A, Wester P, Immerzeel W (2016) Selecting representative climate models for climate change impact studies: an advanced envelope-based selection approach. International Journal of Climatology 36(12):3988-4005, DOI 10.1002/joc.4608

Maloney ED, Camargo SJ, Chang E, Colle B, Fu R, Geil KL, Karnauskas, C KBJJO (2014) DOI 10.1175/JCLI-D-13-00273.1, URL https://doi.org/10. 1175/JCLI-D-13-00273.1

Mandal S, Arunkumar R, Breach PA, Simonovic SP (2019) Reservoir Operations under Changing Climate Conditions: Hydropower-Production Perspective. Journal of Water Resources Planning and Management (5):145-145, DOI 10.1061/(asce)wr.1943-5452.000106110.1061/(ASCE)WR.19435452.0001095

Min SK, Zhang X, Zwiers FW, Friederichs P, Hense AJCD (2009) DOI 10. 1007/s00382-008-0376-8, URL https://doi.org/10.1007/s00382-008-0376-8

Min SK, Zhang X, Zwiers FW, Hegerl GCJN (2011)DOI 10.1038/nature09763, URL https://doi.org/10.1038/nature09763

Minville M, Brissette F, Leconte RJJ (2008) DOI 10.1016/j.jhydrol.2008.05. 033, URL https://doi.org/10.1016/j.jhydrol.2008.05.033

Ongoma V, Chen H, Gao CJT, Climatology A (2019) DOI 10.1007/s00704018-2392-x, URL https://doi.org/10.1007/s00704-018-2392-X

Park C, Min SKJCD (2019) DOI 10.1007/s00382-018-4425-7, URL https: //doi.org/10.1007/s00382-018-4425-7

Peterson DL, Halofsky JEJCS (2018) DOI 10.1016/j.cliser.2017.06.005, URL https://doi.org/10.1016/j.cliser.2017.06.005

Pierce DW, Barnett TP, Santer BD, Gleckler PJ (2009) DOI 10.1073/pnas. 0900094106, URL https://doi.org/10.1073/pnas.0900094106

Reshmidevi T, Kumar DN, Mehrotra R, Sharma AJJOH (2018) DOI 10.1016/ j.jhydrol.2017.02.016,

URL https://doi.org/10.1016/j.jhydrol.2017.02.016

Sa'adi Z, Shiru MS, Shahid S, Ismail TJT (2020) DOI 10.1007/s00704-019-

02948-z, URL https://doi.org/10.1007/s00704-019-02948-z

Sánchez E, Romera R, Gaertner MA, Gallardo C, Castro M (2009) A weighting proposal for an ensemble of regional climate models over Europe driven by 1961-2000 ERA40 based on monthly precipitation probability density functions. Atmospheric Science Letters DOI 10.1002/asl.230

Schulzweida U, Müller R, Kornblüh L, Ansorge C, Quast R (2012) CDOClimate Data Operators-v1. 5.9. Journal Center for Marine Atmospheric Sciences

Seager R, Ting M, Held I, Kushnir Y, Lu J, Vecchi G, Naik, N (2007) Model projections of an imminent transition to a more arid climate in southwestern North America. Science (5828):1181-1184, DOI 10.1126/science.1139601

Seneviratne S, Nicholls N, Easterling D, Goodess C, Kanae S, Kossin J, Rahimi, 
M (2012) DOI 10.7916/d8-6nbt-s431, URL https://doi.org/10.7916/d8$6 n b t$ s431

Shiru MS, Chung ESJT, Climatology A (2021) DOI 10.1007/s00704-02103746-2, URL https://doi.org/10.1007/s00704-021-03746-2

Sillmann J, Kharin VV, Zhang X, Zwiers FW, Bronaugh D (2013a) Climate extremes indices in the CMIP5 multimodel ensemble: Part 1. Model evaluation in the present climate. Journal of Geophysical Research: Atmospheres 118(4):1716-1733, DOI 10.1002/jgrd.50203

Sillmann J, Kharin VV, Zwiers FW, Zhang X, Bronaugh D (2013b) Climate extremes indices in the CMIP5 multimodel ensemble: Part 2. Future climate projections. Journal of Geophysical Research: Atmospheres 118(6):24732493, DOI 10.1002/jgrd.50188

Solomon S, Manning M, Marquis M, Qin D (2007)

Stocker TF, Qin D, Plattner GK, Tignor MM, Allen SK, Boschung J, Midgley, M P (2014)

Tadese MT, Kumar L, Koech RJIJOC (2020) DOI 10.1002/joc.6418, URL https://doi.org/10.1002/joc.6418

Tank AK, Zwiers F, Zhang XJWMO, Geneva S (2009)

Tavakol-Davani H, Nasseri M, Zahraie BJ (2013) DOI 10.1002/joc.3611, URL https://doi.org/10.1002/joc.3611

Taye M, Dyer E, Hirpa F, Charles K (2018) Climate Change Impact on Water Resources in the Awash Basin. Ethiopia Water (11):10-10, DOI 10.3390/w10111560

Taylor KE (2005) Taylor diagram primer. Bulletin of the American meteorological society pp $1-4$

Taylor KE, Stouffer RJ, Meehl GA (2012) An overview of CMIP5 and the experiment design. Bulletin of the American meteorological society 93(4):485-498, DOI 10.1175/BAMS-D-11-00094.1

Tessema N, Kebede A, Yadeta DJIJORBM (2020) Modelling the effects of climate change on streamflow using climate and hydrological models: the case of the Kesem sub-basin of the Awash River basin. Ethiopia, DOI 10. 1080/15715124.2020.1755301, URL https://doi.org/10.1080/15715124.2020. 1755301

Themeß1 MJ, Gobiet A, Heinrich GJCC (2012) DOI 10.1007/s10584-011-02244, URL https://doi.org/10.1007/s10584-011-0224-4

Trzaska S, Schnarr E (2014) A review of downscaling methods for climate change projections. United States Agency for International Development by. Tetra Tech ARD pp 1-42

Warszawski L, Frieler K, Huber V, Piontek F, Serdeczny O, Schewe JJ (2014) DOI 10.1073/pnas.1312330110, URL https://doi.org/10.1073/pnas. 1312330110

Wilby RL, Dawson CW, Barrow EM (2002) SDSM-a decision support tool for the assessment of regional climate change impacts. Journal of Environmental Modelling 17(2):145-157

Wood AW, Leung LR, Sridhar V, Lettenmaier D (2004) Hydrologic implications of dynamical and statistical approaches to downscaling climate model outputs. Climatic change 62(1):189-216, DOI 10.1023/B:CLIM.0000013685. 99609.9e

Zhang X, Alexander L, Hegerl GC, Jones P, Tank AK, Peterson TC, Zwiers, C FWJWIRC (2011) DOI 10.1002/wcc.147, URL https://doi.org/10.1002/ wcc. 147 


\section{Supplementary Files}

This is a list of supplementary files associated with this preprint. Click to download.

- supplementarytablesandgraphs.docx 